\title{
Ionic Dynamics Mediate Spontaneous Termination of Seizures and Postictal Depression State
}

\author{
Giri P. Krishnan and Maxim Bazhenov \\ Department of Cell Biology and Neuroscience, University of California, Riverside, Riverside, California 92521
}

Epileptic seizures are characterized by periods of recurrent, highly synchronized activity that spontaneously terminates, followed by postictal state when neuronal activity is generally depressed. The mechanisms for spontaneous seizure termination and postictal depression remain poorly understood. Using a realistic computational model, we demonstrate that termination of seizure and postictal depression state may be mediated by dynamics of the intracellular and extracellular ion concentrations. Spontaneous termination was linked to progressive increase of intracellular sodium concentration mediated by activation of sodium channels during highly active epileptic state. In contrast, an increase of intracellular chloride concentration extended seizure duration making possible long-lasting epileptic activity characterized by multiple transitions between tonic and clonic states. After seizure termination, the extracellular potassium was reduced below baseline, resulting in postictal depression. Our study suggests that the coupled dynamics of sodium, potassium, and chloride ions play a critical role in the development and termination of seizures. Findings from this study could help identify novel therapeutics for seizure disorder.

\section{Introduction}

Epileptic seizures are defined as "abnormal, excessive, or synchronous neuronal activity in the brain" (Fisher et al., 2005); the occurrence of repetitive seizures is characteristic of epilepsy. A seizure episode generally lasts from a few seconds to minutes and terminates spontaneously, as seen in clinical (Niedermeyer, 2002) and electrophysiological (Steriade, 2003) observations. A seizure that is nonterminating for $>30 \mathrm{~min}$ or recurring within $30 \mathrm{~min}$ is called a status epilepticus. Any seizure lasting for $>5$ min is considered to be a medical emergency and could result in permanent brain injury. The mechanisms of spontaneous seizure termination or the cause of nontermination in status epilepticus are poorly understood.

A particular type of paroxysmal activity called spike-wave seizure, closely resembling the Lennox-Gastaut syndrome in humans (Niedermeyer, 2002), was intensively studied in experiments with anesthetized and nonanesthetized animals. These electrographic spike-wave seizures originate within the neocortex and consist of spike-wave/polyspike-wave complexes recurring at 2-3 $\mathrm{Hz}$, often interrupted by fast runs at $10-15 \mathrm{~Hz}$ (Steriade, 2003). Tonic and bursting states commonly occur several times during seizure with spontaneous transitions between these states. One estimate of duration of these states suggests that a typical spike-wave

Received Nov. 25, 2010; revised March 30, 2011; accepted April 20, 2011.

Author contributions: G.P.K. and M.B. designed research; G.P.K. and M.B. performed research; G.P.K. and M.B. wrote the paper.

This work was supported by NIH-NINDS Grant R01 NS059740. We thank Prof. Igor Timofeev for many stimulating discussions and insightful suggestions.

Correspondence should be addressed to Maxim Bazhenov, Department of Cell Biology and Neuroscience, Genomics \#1207H, University of California, Riverside, Riverside, CA 92521. E-mail: maksim.bazhenov@ucr.edu.

DOI:10.1523/JNEUROSCI.6200-10.2011

Copyright $\odot 2011$ the authors $\quad 0270-6474 / 11 / 318870-13 \$ 15.00 / 0$ seizure episode includes $\sim 80 \%$ of bursting activity and only $20 \%$ of tonic spiking (Boucetta et al., 2008).

Ion concentrations inside the cell and in the extracellular space are known to change during epileptic seizures. Particularly, it was suggested that dynamics of extracellular potassium $\left(\left[\mathrm{K}^{+}\right]_{\mathrm{o}}\right)$ play a critical role in mediating neuronal activity during seizure. It was first observed that the $\left[\mathrm{K}^{+}\right]_{\mathrm{o}}$ increased during spreading depression (Grafstein, 1956). Based on several experimental studies, it was proposed that a positive-feedback loop between extracellular potassium concentration and neural activity could result in seizure (Fertziger and Ranck, 1970). Recent computational studies incorporating extracellular $\mathrm{K}^{+}$concentration dynamics revealed existence of neuronal bistability (coexistence of tonic and clonic states) for a range of $\left[\mathrm{K}^{+}\right]_{\mathrm{o}}$ (Fröhlich et al., 2006; Bazhenov et al., 2008). These findings explained transitions between tonic spiking and bursting commonly observed during epileptic seizures in clinical [Lennox-Gastaut syndrome in humans (Niedermeyer, 2002)] and experimental [electrographic seizures (Steriade, 2003)] settings but failed to reveal mechanisms involved in spontaneous termination of seizures.

In contrast to $\left[\mathrm{K}^{+}\right]_{\mathrm{o}}$, less is known about the changes in intracellular sodium $\left(\left[\mathrm{Na}^{+}\right]_{\mathrm{i}}\right)$ during seizure. Nevertheless, the same arguments explaining $\left[\mathrm{K}^{+}\right]_{\mathrm{o}}$ increase during seizure would suggest a possibility of progressive $\left[\mathrm{Na}^{+}\right]_{\mathrm{i}}$ increase because of the slow nature of $\mathrm{Na}^{+}$ions removal mechanisms. Several lines of experimental evidence suggest the role of $\left[\mathrm{Na}^{+}\right]_{\mathrm{i}}$ in epileptogenesis. First, it was shown that extracellular sodium $\left(\left[\mathrm{Na}^{+}\right]_{\mathrm{o}}\right)$ decreases during epileptiform activity (Meyer et al., 1961; Kraig and Nicholson, 1978; Dietzel et al., 1982; Somjen, 2002), which likely corresponds to increase of $\left[\mathrm{Na}^{+}\right]_{\mathrm{i}}$. Second, evidence comes from studies of conventional antiepileptic drugs. It has been shown experimentally that, although phenytoin (conventional antiepileptic drug affecting $\mathrm{Na}^{+}$channels) increases seizure threshold, it 
also increases seizure duration (Ebert et al., 1997). The last may arise because of slower accumulation of $\left[\mathrm{Na}^{+}\right]_{\mathrm{i}}$ from phenytoinmediated reduction of voltage-sensitive $\mathrm{Na}^{+}$currents. Third, in a recent study, direct measurements of intracellular $\mathrm{Na}^{+}$concentration using high-speed fluorescence imaging showed progressive accumulation of $\mathrm{Na}^{+}$ions during repetitive stimulation in the axonal segment (Fleidervish et al., 2010). Increase of $\left[\mathrm{Na}^{+}\right]_{i}$ was removed by diffusion away from axonal hillock, which occurred at the timescale of several seconds, suggesting a possibility of progressive buildup of $\left[\mathrm{Na}^{+}\right]_{\mathrm{i}}$ during seizure.

In this study, we explored possible mechanisms of spontaneous seizure termination using a realistic computational model of the cortical network, including variable extracellular and intracellular concentrations for $\mathrm{Na}^{+}$and $\mathrm{K}^{+}$ions and variable intracellular concentrations for $\mathrm{Cl}^{-}$and $\mathrm{Ca}^{2+}$ ions. We found that progressive increase in $\left[\mathrm{Na}^{+}\right]_{\mathrm{i}}$ over the course of seizure leads to the changes in balance of excitatory and inhibitory currents that mediate spontaneous seizure termination and may explain postictal depression state. Our results provide testable hypotheses for additional experimental studies and suggest strategies for antiepileptic treatments.

\section{Materials and Methods}

Intrinsic properties of pyramidal cells and interneurons. The pyramidal cells (PYs) and fast-spiking inhibitory interneurons (INs) were modeled as twocompartment neurons with axosomatic and dendritic compartments described using conductance-based approach. The following equations describe the evolution of voltage in time for the two compartments (Mainen and Sejnowski, 1996; Bazhenov et al., 2004; Fröhlich et al., 2006):

$$
\begin{gathered}
C_{\mathrm{m}} d V_{\mathrm{d}} / \mathrm{dt}=-I_{\mathrm{d}}^{\text {Int }}-g_{\mathrm{c}}^{\mathrm{d}}\left(V_{\mathrm{d}}-V_{\mathrm{s}}\right)-I_{\mathrm{d}}^{\text {leak }}-I_{\mathrm{d}}^{\text {pump }} \\
g_{\mathrm{c}}^{\mathrm{s}}\left(V_{\mathrm{d}}-V_{\mathrm{s}}\right)=-I_{\mathrm{s}}^{\text {Int }}-I_{\mathrm{s}}^{\text {leak }}-I_{\mathrm{s}}^{\text {pump }}
\end{gathered}
$$

where $V_{\mathrm{d}}$ is the voltage of the dendritic compartment, $I_{\mathrm{d}}^{\text {leak }}$ includes sodium, potassium, and chloride leak currents $\left(\mathrm{PY}, g_{\mathrm{K}}=0.044, g_{\mathrm{Na}}=0.02\right.$, $\left.g_{\mathrm{Cl}}=0.01 ; \mathrm{IN}, g_{\mathrm{K}}=0.048, g_{\mathrm{Na}}=0.0215, g_{\mathrm{Cl}}=0.003 \mathrm{mS} / \mathrm{cm}^{2}\right), I_{\mathrm{s}}^{\text {leak }}$ includes sodium and potassium leak (PY, $g_{\mathrm{K}}=0.042, g_{\mathrm{Na}}=0.0198 ; \mathrm{IN}, g_{\mathrm{K}}=$ $\left.0.048, g_{\mathrm{Na}}=0.0225 \mathrm{mS} / \mathrm{cm}^{2}\right), I_{\mathrm{d}}^{\text {int }}$ and $I_{\mathrm{s}}^{\text {int }}$ are the sum of intrinsic currents for axosomatic and dendritic compartments, respectively. The $I_{\mathrm{d}}^{\text {pump }}$ and $I_{\mathrm{s}}^{\text {pump }}$ are the sum of $\mathrm{Na}^{+}$and $\mathrm{K}^{+}$ionic currents $\left(I_{\mathrm{Na}}^{\text {pump }}, I_{\mathrm{K}}^{\text {pump }}\right)$ from the $\mathrm{Na}^{+} / \mathrm{K}^{+}$exchange pump for each compartment. The axosomatic and dendritic compartments are coupled by axial current $\left(\mathrm{PY}, g_{\mathrm{c}}=\right.$ $1.65 \mu \mathrm{S} ; \mathrm{IN}, g_{\mathrm{c}}=0.5 \mu \mathrm{S}$ ). As in previous studies (Mainen and Sejnowski, 1996; Bazhenov et al., 2004; Fröhlich et al., 2006), the axosomatic currents are assumed to be strong enough to change the somatic membrane voltage instantaneously; thus, there is no capacitance current for the axosomatic compartment in this model. This assumption allows using a larger integration time step size, resulting in increased computational efficiency while still reproducing biophysically realistic neuronal activity. The current from $\mathrm{Na}^{+} / \mathrm{K}^{+}$pump was determined by $\left[\mathrm{Na}^{+}\right]_{\mathrm{i}}$ and $\left[\mathrm{K}^{+}\right]_{\mathrm{o}}$ and was given by the following equations (Kager et al., 2000; Bazhenov et al., 2004):

$$
\begin{gathered}
A=\left(1 /\left(1+\left(\mathrm{K}_{\mathrm{o} \alpha} /\left[\mathrm{K}_{\alpha}\right]\right)\right)^{2}\left(1 /\left(1+\left(\mathrm{Na}_{\mathrm{i} \alpha} / \mathrm{Na}_{\mathrm{i}}\right]\right)\right)^{3}\right. \\
I_{\mathrm{k}}^{\text {pump }}=-2 I_{\max } A \quad I_{\mathrm{Na}}^{\text {pamp }}=3 \mathrm{I}_{\max } A
\end{gathered}
$$

where $\mathrm{K}_{\mathrm{o} \alpha}=2.5 \mathrm{mM}$ and $\mathrm{Na}_{\mathrm{i} \alpha}=20 \mathrm{mM}$, and $I_{\max }=20 \mathrm{~mA} / \mathrm{cm}^{2}$.

In general, all intrinsic currents were given by the following equation:

$$
I_{i}=G_{i} m^{a} h^{b}\left(V-E_{i}\right),
$$

where $G_{i}$ is the maximal conductance, $m$ and $h$ are gating variables, and $E_{i}$ is the reversal potential. The gating variables are given by either its steadystate value $\left(m_{\infty}, h_{\infty}\right)$ or by the following differential equations:

$$
\begin{aligned}
d m / d t & =\left[m_{\infty}(V)-m\right] / \tau_{m}(V) \\
d h / d t & =\left[h_{\infty}(V)-h\right] / \tau_{h}(V) .
\end{aligned}
$$

The set of intrinsic currents of axosomatic compartment $\left(I_{\mathrm{s}}^{\mathrm{nt}}\right)$ consisted of voltage-gated sodium (PY, $G_{\mathrm{Na}}=3450 \mathrm{mS} / \mathrm{cm}^{2} ; \mathrm{IN}, G_{\mathrm{Na}}=3800 \mathrm{mS} / \mathrm{cm}^{2}$ ) and a delayed-rectifier potassium (PY and IN, $G_{\mathrm{Kv}}=200 \mathrm{mS} / \mathrm{cm}^{2}$ ) currents. The axosomatic compartment of the pyramidal neuron also included persistent sodium $\left(G_{\mathrm{NaP}}=3.5 \mathrm{mS} / \mathrm{cm}^{2}\right)$ and sodium-activated potassium channels $\left(G_{\mathrm{KNa}}=1.3 \mathrm{mS} / \mathrm{cm}^{2}\right)$. The dendritic compartment had high-threshold calcium, $I_{\mathrm{Ca}}$, calcium-activated potassium $I_{\mathrm{KCa}}$, slowly activating potassium, $I_{\mathrm{Km}}$, persistent sodium, $I_{\mathrm{NaP}}$, hyperpolarization-activated depolarizing mixed cationic, $I_{\mathrm{h}}$, voltage-gated sodium $\left(I_{\mathrm{Na}}\right)$, and leak conductances $\left(\mathrm{PY}, G_{\mathrm{Ca}}=0.0165 ; G_{\mathrm{KCa}}=2.5 ; G_{\mathrm{Km}}=0.01 ; G_{\mathrm{NaP}}=3.5 ; G_{\mathrm{h}}=0.1 \mathrm{mS} / \mathrm{cm}^{2}\right.$; $\left.G_{\mathrm{Na}}=1.1 ; \mathrm{IN}, G_{\mathrm{h}}=0.1, G_{\mathrm{Na}}=1.0 \mathrm{mS} / \mathrm{cm}^{2}\right)$.

The following set of equations describes the evolution of intrinsic currents and gating variables over time:

Voltage-sensitive sodium current:

$$
\begin{gathered}
I_{\mathrm{Na}}=G_{\mathrm{Na}} m^{3} h\left(V-E_{\mathrm{Na}}\right) \\
m_{\infty}=a_{m} /\left(a_{m}+b_{m}\right), \tau_{m}=\left(1 /\left(a_{m}+b_{m}\right)\right) / \phi, \\
a_{m}=0.182(v+25) /(1-\exp ((-V-25) / 9)), \\
b_{m}=0.124(-V-25) /(1-\exp ((V+25) / 9)), \\
h_{\infty}=1 /(1+\exp ((V+55) / 6.2)), \tau_{h}=\left(1 /\left(a_{h}+b_{h}\right)\right) / \phi,
\end{gathered}
$$

where $\phi=2.95$

Delayed-rectifier potassium current:

$$
I_{K}=\phi G_{k} m(V-e K s), m_{\infty}=a /(a+b), \tau=1 /(\phi(a+b)),
$$

where $a=0.02(V-25) /(1-\exp ((-V+25) / 9)), b=-0.002(V-$ $25) /(1-\exp ((V-25) / 9))$.

Persistent sodium current (Alzheimer et al., 1993):

$$
I_{\text {Nap }}=G_{\text {Nap }} m\left(V-E_{N a}\right), m_{\infty}=1 / 1+\exp [(-\mathrm{V}-42) / 5], \tau_{\mathrm{m}}=0.02,
$$

Mixed cation current:

$$
I_{h}=G_{h} m\left(V-E_{h}\right), \tau_{m}=38, m_{\infty}=1 /(1+\exp ((V+82) / 7)),
$$

Sodium-sensitive potassium current (Wang et al., 2003):

$$
I_{\mathrm{NaK}}=g_{\mathrm{NaK}}\left(\mathrm{V}-\mathrm{E}_{\mathrm{K}}\right), g_{\mathrm{NaK}}=G_{\mathrm{NaK}} 0.37 /\left(1+\left(77.4 /\left[N a_{\mathrm{i}}\right]\right)^{3.5}\right),
$$

Slowly activating potassium current:

$$
\begin{gathered}
I_{\mathrm{K} m}=\phi G_{\mathrm{K} m} m\left(V-E_{\mathrm{k}}\right), \\
m_{\infty}=a_{m} /\left(a_{m}+b_{m}\right), \tau_{m}=1 /\left(\phi\left(a_{m}+b_{m}\right)\right), \\
(V+30) /(1-\exp (-(V+30) / 9), \\
b_{m}=-0.001(V+30) /(1-\exp ((V+30) / 9)),
\end{gathered}
$$$$
a_{m}=0.001(V+30) /(1-\exp (-(V+30) / 9) \text {, }
$$

High-threshold calcium current:

$$
\begin{gathered}
I_{\mathrm{Ca}}=\phi G_{\mathrm{Ca}} m^{2} h\left(V-E_{\mathrm{Ca}}\right), \\
m_{\infty}=a_{m} /\left(a_{m}+b_{m}\right), \tau_{m}=1 /\left(\phi\left(a_{m}+b_{m}\right)\right), \\
-27-V) /(\exp ((-27-V) / 3.8)-1), \\
b_{m}=0.94 \exp ((-75-V) / 17), \\
h_{\infty}=a_{h} /\left(a_{h}+b_{h}\right), \tau_{h}=1 /\left(\phi\left(a_{h}+b_{h}\right)\right),
\end{gathered}
$$$$
a_{m}=0.055(-27-V) /(\exp ((-27-V) / 3.8)-1) \text {, }
$$

$a_{h}=4.57 \times 10^{-4} \exp ((-13-V) / 50)$,

$$
b_{h}=6.5 \times 10^{-3} /(\exp ((-V-15) / 28)+1),
$$

Calcium-sensitive potassium current:

$$
I_{\mathrm{KCa}}=G_{\mathrm{KCa}} m^{2}\left(V-E_{\mathrm{K}}\right)
$$

$m_{\infty}=\left(1600[\mathrm{cai}]^{2}\right) /\left(1600[\mathrm{cai}]^{2}+1\right)$,

$$
\tau=\left(1 /\left(0.03\left(1600[\mathrm{cai}]^{2}+1\right)\right)\right) / 4.6555 .
$$


Ion concentration dynamics. The model included variable concentrations for $\left[\mathrm{Ca}^{2+}\right]_{\mathrm{i}},\left[\mathrm{K}^{+}\right]_{\mathrm{o}},\left[\mathrm{K}^{+}\right]_{\mathrm{i}},\left[\mathrm{Na}^{+}\right]_{\mathrm{o}},\left[\mathrm{Na}^{+}\right]_{\mathrm{i}}$, and $\left[\mathrm{Cl}^{-}\right]_{\mathrm{i}}$. The concentration of each ion was determined by leak currents, intrinsic currents, pump-mediated currents, extracellular diffusion, and glial activity. The evolution of $\left[\mathrm{K}^{+}\right]_{\mathrm{o}}$ was modeled similar to previous studies (Kager et al., 2000; Bazhenov et al., 2004; Fröhlich et al., 2006) and was given by the following:

$$
\begin{gathered}
d\left[\mathrm{~K}^{+}\right]_{\mathrm{o}} / d t=(k / F d)\left(I_{\Sigma \mathrm{K}}^{\mathrm{Int}}+I_{k}^{\text {pump }}\right)+G+\delta_{\mathrm{o}}\left(\left(\left[\mathrm{K}^{+}\right]_{\mathrm{o}-1}\right.\right. \\
\left.\left.+\left[\mathrm{K}^{+}\right]_{\mathrm{o}+1}\right) / 2-\left[\mathrm{K}^{+}\right]_{\mathrm{o}}\right)+\delta_{\mathrm{o}}\left(\left[\mathrm{K}^{+}\right]_{\mathrm{oc}}-\left[\mathrm{K}^{+}\right]_{\mathrm{o}}\right) \\
G=k_{1}\left([\mathrm{~B}]_{\max }-[\mathrm{B}]\right) / k_{1 N}-k 2\left[\mathrm{~K}^{+}\right]_{\mathrm{o}}[\mathrm{B}] \\
d[\mathrm{~B}] / d t=k_{1}\left([\mathrm{~B}]_{\max }-[\mathrm{B}]\right)-k_{2}\left[\mathrm{~K}^{+}\right]_{\mathrm{o}}[\mathrm{B}]
\end{gathered}
$$

where $k$ (conversion factor $)=10, F=96489 \mathrm{C} / \mathrm{mol}, d(=0.15)$ determined the ratio of the volume of the extracellular compartment to the surface area, $\left[\mathrm{K}^{+}\right]_{\mathrm{oc}}$ is the concentration of $\mathrm{K}^{+}$in the adjacent compartment, $\left[\mathrm{K}^{+}\right]_{\mathrm{o}-1}$ and $\left[\mathrm{K}^{+}\right]_{\mathrm{o}+1}$ or $\left[\mathrm{Na}^{+}\right]_{\mathrm{o}-1}$ and $\left[\mathrm{Na}^{+}\right]_{\mathrm{o}+1}$ are the concentration from neighboring cells. Glial $\mathrm{K}^{+}$uptake current was modeled by a free buffer (total buffer $[\mathrm{B}]_{\max }=500 \mathrm{~mm}$ ) with concentration $[\mathrm{B}]$, which bound and unbound from $\mathrm{K}^{+}$based on the first-order kinetics with rates $k_{1}$ and $k_{2}$ given by $k_{1}=0.008$ and $k_{2}=k_{1} /\left(1+\exp \left(\left(\left[\mathrm{K}^{+}\right]_{\mathrm{o}}-\right.\right.\right.$ $\left.\left.\left.\left[\mathrm{K}^{+}\right]_{\mathrm{oth}}\right) /-1.15\right)\right)$. The equations for the other three concentrations are given as follows:

$$
\begin{gathered}
d\left[\mathrm{~K}^{+}\right]_{\mathrm{i}} / d t=-(k / F)\left(I_{\Sigma \mathrm{K}}^{\mathrm{Int}}+I_{k}^{\mathrm{pump}}\right)+\delta_{\mathrm{i}}\left(\left[\mathrm{K}^{+}\right]_{\mathrm{ic}}-\left[\mathrm{K}^{+}\right]_{\mathrm{o}}\right) \\
d\left[\mathrm{Na}^{+}\right]_{\mathrm{o}} / d t=(k / F d)\left(I_{\Sigma \mathrm{Na}}^{\mathrm{Int}}+I_{\mathrm{Na}}^{\mathrm{pump}}\right)+\delta_{\mathrm{o}}\left(\left[\mathrm{Na}^{+}\right]_{\mathrm{o}-1}+\left[\mathrm{Na}^{+}\right]_{\mathrm{o}+1}\right) / \\
\left.2-\left[\mathrm{Na}^{+}\right]_{\mathrm{o}}\right)+\delta_{\mathrm{o}}\left(\left[\mathrm{Na}^{+}\right]_{\mathrm{oc}}-\left[\mathrm{Na}^{+}\right]_{\mathrm{o}}\right) \\
d\left[\mathrm{Na}^{+}\right]_{\mathrm{i}} / d t=-(k / F)\left(I_{\Sigma \mathrm{Na}}^{\mathrm{Int}}+I_{\mathrm{Na}}^{\text {pump }}\right)+\delta_{\mathrm{i}}\left(\left[\mathrm{Na}^{+}\right]_{\mathrm{ic}}-\left[\mathrm{Na}^{+}\right]_{\mathrm{o}}\right) .
\end{gathered}
$$

The intracellular chloride concentration varied based on the following equations:

$$
\begin{gathered}
d\left[\mathrm{Cl}^{-}\right]_{\mathrm{i}} / d t=-(k / F) I_{\Sigma \mathrm{Cl}}^{\mathrm{Int}}+\left(\left[\mathrm{Cl}^{-}\right]_{\mathrm{i}}-\left[\mathrm{Cl}^{-}\right]_{\mathrm{i} \infty}\right) / \tau_{\mathrm{cl}} \\
\tau_{c l}=\left(100+\tau_{C l \infty} /\left(1+\exp \left(\left(\left[\mathrm{Cl}^{-}\right]_{i \infty}-\left[\mathrm{K}^{+}\right]_{o}\right) / \tau_{\text {Kocl }}\right)\right)\right),
\end{gathered}
$$

where $\left[\mathrm{Cl}^{-}\right]_{\mathrm{i} \infty}=5 \mathrm{mM}, \tau_{\mathrm{Kocl}}=0.08 \mathrm{~s}, \tau_{\mathrm{Cl} \infty}=2 \times 10^{4}$, and $k=100$. These parameter values were chosen to match the experimental data regarding the effect of $\left[\mathrm{K}^{+}\right]_{\mathrm{o}}$ on the efficiency of KCC2 pump (Payne et al., 2003). The last equation represents one of the isoforms of the $\mathrm{K}-\mathrm{Cl}$ cotransporters that uses electrochemical gradient of $\mathrm{K}^{+}$to move both $\mathrm{K}^{+}$and $\mathrm{Cl}^{-}$ ions outward. The intracellular calcium concentration was given by the following:

$$
d[\mathrm{Ca}]_{\mathrm{i}} / d t=-5.1819 \times 10^{-5} I_{\mathrm{HVA}} / D_{\mathrm{Ca}}+\left(2.4 \times 10^{-4}-[\mathrm{cai}]\right) / \tau_{\mathrm{ca}},
$$

where $\tau_{\mathrm{ca}}=300 \mathrm{~ms}$ and $D_{\mathrm{Ca}}=0.85$.

The reversal potential for each current was determined by Nernst equation for the ions passing through the respective channels $\left[E_{\mathrm{K}}=e_{0} \log \left(\left[\mathrm{K}_{\mathrm{o}}\right] /\right.\right.$ $\left.\left[\mathrm{K}_{\mathrm{i}}\right]\right), E_{\mathrm{Na}}=e_{0} \log \left(\left[\mathrm{Na}_{\mathrm{o}}\right] /\left[\mathrm{Na}_{\mathrm{i}}\right]\right), e H=e_{0} \log \left(\left(\left[\mathrm{K}_{\mathrm{o}}\right]+0.2\left[\mathrm{Na}_{\mathrm{o}}\right]\right) /\left(\left[\mathrm{K}_{\mathrm{i}}\right]+\right.\right.$ $\left.\left.0.2\left[\mathrm{Na}_{\mathrm{i}}\right]\right)\right), E_{\mathrm{Cl}}=e_{0} \log \left(\left[\mathrm{Cl}_{\mathrm{i}}\right] / 130.0\right)$, where $\left.e_{0}=26.64\right]$.

When Poisson noise was used in a network model, few changes were made to the neuronal model. Changes that were made included increasing conductance of the leak current (PY: soma, $g K l=0.047$; dendrite, $g K l=0.044$; IN: soma, $g K l=0.048$; dendrite, $g K l=0.047)$ as seen in the study by van Welie et al. (2006), reduction of conductances for highthreshold $\left[\mathrm{Ca}^{2+}\right]\left(G_{\mathrm{Ca}}=0.013\right)$ (O'Leary et al., 2010) and fast sodium currents (PY and IN: $G_{\mathrm{Na}}=3000$ ) (Grubb and Burrone, 2010), and increasing conductance for chloride leak current (PY: $g_{\mathrm{Cl}}=0.014$; IN: $g_{\mathrm{Cl}}=$ 0.013 ) and sodium leak current (PY: soma, $g_{\mathrm{Na}}=0.0212$; dendrite, $g_{\mathrm{Na}}=$ 0.021; IN: soma and dendrite, $\left.g_{\mathrm{Na}}=0.024\right)$.

Synaptic connections and network topology. For both small and large networks, synaptic connectivity was random (connection probability, $p=0.1$ ) with doubled value of $p$ within local footprint (radii: PY-PY, 5; PY-IN, 1; IN-PY, 5). All excitatory connections had a fast AMPA and a slow voltage-dependent NMDA components [total conductances:
$g_{\mathrm{AMPA}}(\mathrm{PY}-\mathrm{PY})=9 \mathrm{nS} ; g_{\mathrm{NMDA}}(\mathrm{PY}-\mathrm{PY})=0.9 \mathrm{nS} ; g_{\mathrm{AMPA}}(\mathrm{PY}-\mathrm{IN})=$ $\left.3.0 \mathrm{nS} ; g_{\mathrm{NMDA}}(\mathrm{PY}-\mathrm{IN})=0.30 \mathrm{nS}\right]$. Inhibition was mediated by fast $\mathrm{GABA}_{\mathrm{A}}$ synaptic conductances $\left[g_{\mathrm{GABA}}(\mathrm{IN}-\mathrm{PY})=9 \mathrm{nS}\right]$. Afferent excitatory input ( $g_{\mathrm{PY}}=1.1 \mathrm{nS} ; g_{\mathrm{IN}}=1.1 \mathrm{nS}$ ) was modeled with a Poisson process with frequency $f=140 \mathrm{~Hz}$ for both PYs and INs in case of large network. All synaptic currents were modeled by first-order activation schemes (Destexhe et al., 1994; Timofeev et al., 2000) and are given by the following:

$$
\begin{gathered}
I_{\text {syn }}=g_{\text {syn }}[\mathrm{O}]\left(V-E_{\mathrm{syn}}\right) \\
d[\mathrm{O}] / d t=\alpha(1-[\mathrm{O}])[\mathrm{T}]-\beta[\mathrm{O}] \\
{[T]=A \Theta\left(t_{0}+t_{\max }-t\right) \Theta\left(t-t_{0}\right),}
\end{gathered}
$$

where $\Theta(x)$ is the Heaviside function, and $t_{0}$ is the time of spike. The parameters for the neurotransmitter pulse were amplitude $A=0.5$ and duration $t_{\max }=0.3 \mathrm{~ms}$. The rate constants, $\alpha$ and $\beta$, were $\alpha=10 \mathrm{~ms}$ and $\beta=0.25 \mathrm{~ms}$ for $\mathrm{GABA}_{\mathrm{A}}$ synapses and $\alpha=0.94 \mathrm{~ms}$ and $\beta=0.18 \mathrm{~ms}$ for AMPA synapses. In this model, postsynaptic events were generated only when presynaptic membrane voltage exceeded zero threshold. Therefore, synaptic transmission was absent during depolarization block. This model dynamic was consistent with recent findings of the abolition of evoked synaptic responses during experimental seizures (Seigneur and Timofeev, 2011).

A short-term synaptic depression was included in which the maximal synaptic conductance was multiplied by a depression variable $(D \leq 1)$ (Tsodyks and Markram, 1997). This variable represents the amount of available synaptic resources and was varied based on the following equation:

$$
D=1-\left(1-D_{i}(1-U)\right) \exp \left(-\left(t-t_{i}\right) / \tau\right),
$$

where $U=0.07$ is the fraction of resources used per action potential, $\tau=$ $700 \mathrm{~ms}$ is the time constant of recovery of the synaptic resources, $D_{i}$ is the value of $D$ just before the $i$ th event, and $\left(t-t_{i}\right)$ is the time since the $i$ th event.

A fourth-order Runge-Kutta method was used for all integration. For the bifurcation analysis, XPP-AUTO (Ermentrout, 2002) was used.

To ensure structural stability of the model dynamics, the main properties of the model, including stability of the baseline asynchronous state, existence of transitions between tonic and clonic activity, and termination of seizure, were tested against synaptic and intrinsic parameter change. This included varying of synaptic coupling, maximal conductances of intrinsic currents, and parameters characterizing dynamics of different ions.

\section{Results}

The neuron dynamics were modeled using a conductance-based model, which included axosomatic and dendritic compartments and was derived from the studies by Bazhenov et al. (2004) and Fröhlich et al. (2006). The selection of currents (see Materials and Methods) was determined by the goal of describing the major known electrical properties of cortical neurons. Specifically, we used a model of regular spiking cells for excitatory neurons and fast spiking cells for inhibitory interneurons (Mainen and Sejnowski, 1996). Reversal potentials for the ions passing through the membrane were determined by the ion concentrations. The change in ion concentrations was computed based on the currents entering and leaving the neuron through active channels, $\mathrm{Na}^{+} / \mathrm{K}^{+}$exchange pump, KCC2 pump, and ion flow in the extracellular space mediated by diffusion. Additionally, glial buffering was simulated to control $\left[\mathrm{K}^{+}\right]_{\mathrm{o}}$. To simulate electrogenic properties of the $\mathrm{Na}^{+} / \mathrm{K}^{+}$exchange pump, both cell compartments included currents mediated by the pump.

Despite the complexity of the ionic dynamics, this model achieved stable equilibrium with all the ion flows balancing each other, and membrane voltage stabilized at the physiological rest- 

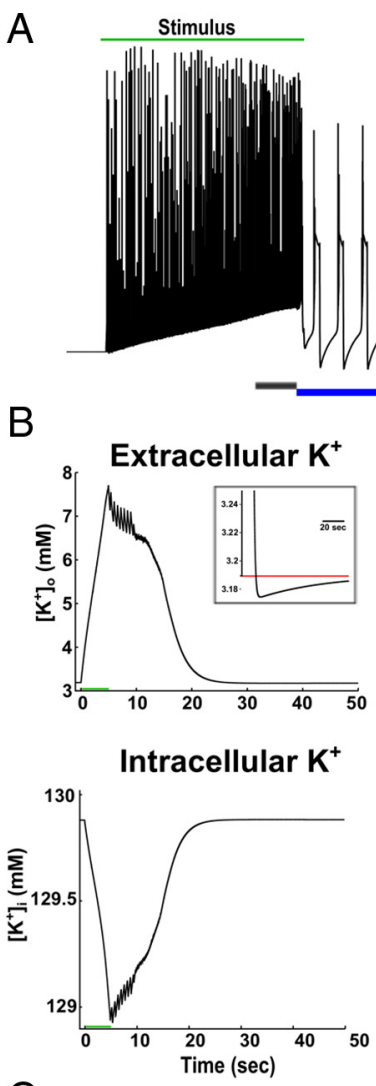

C
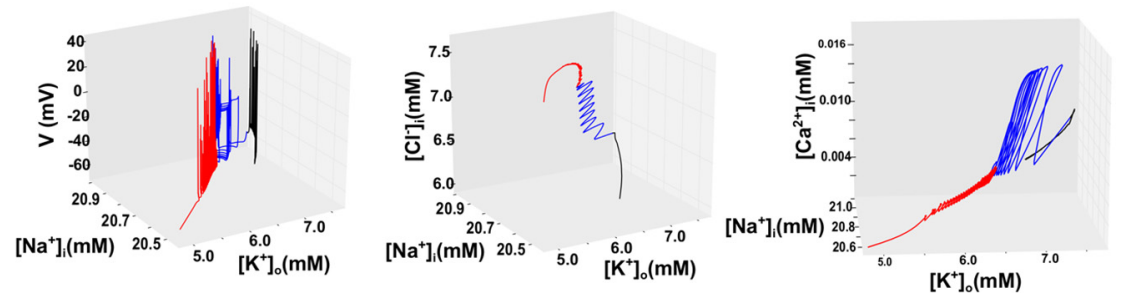

Figure 1. Transient seizure-like activity in the isolated pyramidal neuron. $\boldsymbol{A}$, After brief $(5 s) D C$ stimulation (green line at the top), the neuron displayed self-sustained paroxysmal activity including bursting (indicated by blue line) and tonic spiking (red line) episodes. $\boldsymbol{B}$, Dynamics of ion concentrations over time. $\left[\mathrm{K}^{+}\right]_{0}$ and $\left[\mathrm{Na}^{+}\right]_{\mathrm{i}}$ increased during $\mathrm{DC}$ stimulation (green bar) and then progressively decreased while $\left[\mathrm{Cl}^{-}\right]_{\mathrm{i}}$ continued to build up until the end of paroxysmal state. The inset shows decrease of $\left[\mathrm{K}^{+}\right]_{0}$ below baseline immediately after termination of seizure. $\boldsymbol{C}$, Three-dimensional projections of the state trajectory during transient seizure-like activity indicate coupled dynamics of $\left[\mathrm{K}^{+}\right]_{0^{\prime}}\left[\mathrm{Na}^{+}\right]_{\mathrm{i}},\left[\mathrm{Cl}^{-}\right]_{\mathrm{i}^{\prime}}\left[\mathrm{Ca}^{2+}\right]_{\mathrm{i}^{\prime}}$ and membrane voltage. The black, blue, and red portions of the trajectory correspond to the color bars in $\boldsymbol{A}$.

ing potential, $V_{\mathrm{m}}=-65 \mathrm{mV}$. Sufficiently small external perturbations decayed in time, and the membrane voltage returned to the resting state.

\section{State transitions mediated by ionic dynamics in a single-cell model}

To elaborate response properties of a single model neuron, direct current (DC) input was applied to an isolated cell to elicit a brief period of high-frequency spiking activity (Fig. $1 \mathrm{~A}$ ). This resulted in a flow of $\mathrm{K}^{+}$ions to the extracellular space and a gradual increase in the $\left[\mathrm{K}^{+}\right]_{\mathrm{o}}$ during the stimulation period (Fig. $1 B$ ). After the termination of DC input, the neuron exhibited a period of bursting activity (with transient depolarization block during each burst) and then tonic spiking activity, before returning to the resting state (Fig. $1 \mathrm{~A}$ ). These findings are similar to our previous results with simpler model that only included $\left[\mathrm{K}^{+}\right]_{\mathrm{o}}$ and $\left[\mathrm{Ca}^{2+}\right]_{\mathrm{i}}$ dynamics (Bazhenov et al., 2004; Fröhlich et al., 2006) and show that this new model including variable $\left[\mathrm{Na}^{+}\right]_{\mathrm{i} / \mathrm{o}},\left[\mathrm{K}^{+}\right]_{\mathrm{i} / \mathrm{o}},\left[\mathrm{Cl}^{-}\right]_{\mathrm{i}}$, and $\left[\mathrm{Ca}^{2+}\right]_{i}$ is capable of generating selfsustained transient bursting and tonic activity.

The $\left[\mathrm{K}^{+}\right]_{\mathrm{o}}$ progressively decreased after termination of DC input, reaching values slightly below baseline (Fig. $1 B$ ). The $\left[\mathrm{Na}^{+}\right]_{\mathrm{i}}$ increased during DC stimulation and decreased after its termination. In contrast to $\left[\mathrm{K}^{+}\right]_{\mathrm{o}}$, however, $\left[\mathrm{Na}^{+}\right]_{\mathrm{i}}$ returned slower to the baseline; since sodium and potassium ion concentrations are coupled in our model through the $\mathrm{Na}^{+} / \mathrm{K}^{+}$exchange pump, that led to decrease of the $\left[\mathrm{K}^{+}\right]_{\mathrm{o}}$ below baseline after termination of activity. The intracellular calcium $\left(\left[\mathrm{Ca}^{2+}\right]_{\mathrm{i}}\right)$ increased during the stimulus and showed oscillatory activity during the bursting period (Fig. $1 \mathrm{~B}$ ). Finally, the $\left[\mathrm{Cl}^{-}\right]_{\mathrm{i}}$ increased during the stimulation period reaching $\sim 7.5 \mathrm{~mm}$. In normal physiological conditions, KCC2 pump uses the difference in $\mathrm{K}^{+}$across the membrane to transport $\mathrm{Cl}^{-}$and $\mathrm{K}^{+}$ions to maintain a low level of $\left[\mathrm{Cl}^{-}\right]_{\mathrm{i}}$ at $\sim 5 \mathrm{mM}$ (DeFazio et al., 2000). Experimentally, increase of $\left[\mathrm{K}^{+}\right]_{\mathrm{o}}$ to $9 \mathrm{~mm}$ reduces efficiency of this pump and can lead to increase in $\left[\mathrm{Cl}^{-}\right]_{\mathrm{i}}$ to $\sim 10 \mathrm{~mm}$ (Payne et al., 2003). Therefore, increase in $\left[\mathrm{Cl}^{-}\right]_{\mathrm{i}}$ in our model was attributable to the increase in $\mathrm{Cl}^{-}$ leak currents and inactivation of KCC2 pump by elevated $\left[\mathrm{K}^{+}\right]_{\mathrm{o}}$. Approximately 1-2 $\mathrm{s}$ after termination of activity, the $\mathrm{Cl}^{-}$ pump mediated $\left[\mathrm{Cl}^{-}\right]_{\mathrm{i}}$ return to the baseline.

The three-dimensional plots in Figure $1 C$ show the evolution of voltage and ion concentrations during DC input and selfsustained activity from various projections of the state space (state space is defined as a high dimensional space with all the variables of the model as individual dimensions). Notably, within these plots are distinct regions in the state space that correspond to different states of activity of the neuron. Such segregation of regions, when plotted against the ion concentrations, suggests a strong coupling between different ion concentrations in our model. Indeed, the change in one ion concentration resulted in change of neuronal activity, which in turn resulted in changes in other ion concentrations, leading to a specific trajectory in the state space. For example, increase in $\left[\mathrm{K}^{+}\right]_{\mathrm{o}}$ led to (1) corresponding increase in $\left[\mathrm{Na}^{+}\right]_{\mathrm{i}}$ (Fig. $1 C$, left) because of increased firing of the neuron, and (2) nonlinear increase in $\left[\mathrm{Cl}^{-}\right]_{\mathrm{i}}$ and $\left[\mathrm{Ca}^{2+}\right]_{\mathrm{i}}$ (Fig. $1 C$, middle and right).

\section{Spontaneous seizure termination in a network model}

We previously found that when neuron models incorporating $\left[\mathrm{K}^{+}\right]_{\mathrm{o}}$ and $\left[\mathrm{Ca}^{2+}\right]_{\mathrm{i}}$ dynamics were connected to create a network, it led to continuous transitions between slow bursting and tonic firing mediated by slow $\left[\mathrm{K}^{+}\right]_{\mathrm{o}}$ oscillations (Fröhlich et al., 2006). Thus, this earlier model was able to describe experimental obser- 
vations of state transitions between tonic and clonic states of seizure (Steriade, 2003), although it failed to explain termination of paroxysmal oscillations.

To explore the effect of synaptic connectivity in the new model incorporating $\left[\mathrm{Na}^{+}\right]_{\mathrm{i} / \mathrm{o}},\left[\mathrm{K}^{+}\right]_{\mathrm{i} / \mathrm{o}},\left[\mathrm{Cl}^{-}\right]_{\mathrm{i}}$, and $\left[\mathrm{Ca}^{2+}\right]_{\mathrm{i}} \mathrm{dy}-$ namics, a small network of 10 pyramidal neurons and 2 inhibitory interneurons was stimulated by DC input applied to all pyramidal neurons. In this simple model, all excitatory pyramidal cells were connected with AMPA- and NMDA-type synapses and projected to two inhibitory interneurons, which provided $\mathrm{GABA}_{\mathrm{A}^{-}}$ type feedback inhibition to pyramidal cells. Figure 2, $A$ and $B$, shows the activity of a single representative pyramidal neuron and a raster plot of activities of all pyramidal neurons in the network. After stimulus offset (stimulus duration is marked with green bar in Fig. 2A), the network exhibited a series of selfsustained tonic and bursting periods lasting for $\sim 100 \mathrm{~s}$ total before terminating, with bursting lasting $\sim 75 \%$ of the total seizure duration. Excitatory cells displayed trains of single spikes or spike doublets during tonic phase and periodic bursting with typical PDS waveform during clonic phase of oscillations. These bursts typically included few spikes at the beginning of the burst depolarization, few spikes at the end, with no spiking throughout the middle of the burst. The exact pattern depended on the level of $\left[\mathrm{K}^{+}\right]_{\mathrm{o}}$ (Fröhlich and Bazhenov, 2006). This wave form is typical for paroxysmal depolarization shift observed during cortical epileptic seizures (Timofeev et al., 2002; Timofeev and Steriade, 2004). Inhibitory interneurons fired continuously during periods when pyramidal neurons were bursting but were usually silent during tonic spiking epochs (Fig. 2C). This finding was in agreement with experimental data (Timofeev et al., 2002) and suggested that excitatory drive from pyramidal cells was not sufficiently synchronized during tonic spiking to trigger reliable responses of inhibitory interneurons (Fig. 2D). In contrast, during network bursting, all pyramidal neurons fired synchronously, leading to large amplitude excitatory currents from pyramidal to inhibitory neurons that mediated interneuron activity during bursting epochs.

Similar to results obtained with a single-cell model (Fig. 1), the $\left[\mathrm{K}^{+}\right]_{\mathrm{o}}$ increased during transient network stimulation and then oscillated for the duration of seizure (Fig. 3A). The dynamics of $\left[\mathrm{K}^{+}\right]_{\mathrm{o}}$ was closely tied to the spiking frequency; thus, it decreased during bursting and increased during tonic spiking periods. A transition from tonic spiking to bursting occurred at a higher level of $\left[\mathrm{K}^{+}\right]_{\mathrm{o}}$ compared with a transition from bursting back to tonic mode. This was a result of bistability: tonic spiking and bursting regimens coexisted for a range of $\left[\mathrm{K}^{+}\right]_{\mathrm{o}} \in\left[\left[\mathrm{K}^{+}\right]_{\mathrm{o}}{ }^{(1)}\right.$, $\left.\left[\mathrm{K}^{+}\right]_{\mathrm{o}}{ }^{(2)}\right]$ (Fröhlich and Bazhenov, 2006) (for more details, see Fig. 4). The neuron stayed in tonic spiking mode (in this state, the outward flow of $\mathrm{K}^{+}$was higher than $\mathrm{K}^{+}$regulatory mechanisms could accommodate, which led to overall increase of $\left.\left[\mathrm{K}^{+}\right]_{\mathrm{o}}\right)$ until $\left[\mathrm{K}^{+}\right]_{\mathrm{o}}$ reached the high boundary of bistability region $\left[\mathrm{K}^{+}\right]_{\mathrm{o}}=$ $\left[\mathrm{K}^{+}\right]_{\mathrm{o}}{ }^{(2)}$ when the neuron switched to periodic bursting. Since the overall outward flow of $\mathrm{K}^{+}$was lower in this state, $\left[\mathrm{K}^{+}\right]_{\mathrm{o}}$ decreased until it reached the low boundary of bistability $\left[\mathrm{K}^{+}\right]_{\mathrm{o}}=$ $\left[\mathrm{K}^{+}\right]_{\mathrm{o}}{ }^{(1)}$, followed by switching back to tonic spiking; this led to repetitive transitions. However, in this new model, transitions between two active states did not last indefinitely but terminated after only a few cycles. The total duration of the active state was $\sim 100 \mathrm{~s}$, which is consistent with typical seizure duration studied in vivo (Timofeev and Steriade, 2004). After termination of seizure, $\left[\mathrm{K}^{+}\right]_{\mathrm{o}}$ showed a reduction below baseline (Fig. $3 A$ ). Similar reduction in $\left[\mathrm{K}^{+}\right]_{\mathrm{o}}$ below baseline has been observed experimentally (Heinemann et al., 1977; Jensen and Yaari, 1997) (Fig. 3B).

To reveal factors contributing to termination of paroxysmal oscillations, we examined the dynamics of sodium and chloride ion concentrations (Fig. $3 C-F$ ). The $\left[\mathrm{Na}^{+}\right]_{\mathrm{i}}$ rapidly increased during stimulation phase and then showed oscillatory pattern similar to $\left[\mathrm{K}^{+}\right]_{\mathrm{o}}$ along with an increment at every transition from bursting to tonic states (Fig. 3C). In contrast to the single-cell model (Fig. $1 B$ ), both $\left[\mathrm{K}^{+}\right]_{\mathrm{o}}$ and $\left[\mathrm{Na}^{+}\right]_{\mathrm{i}}$ increased during tonic 

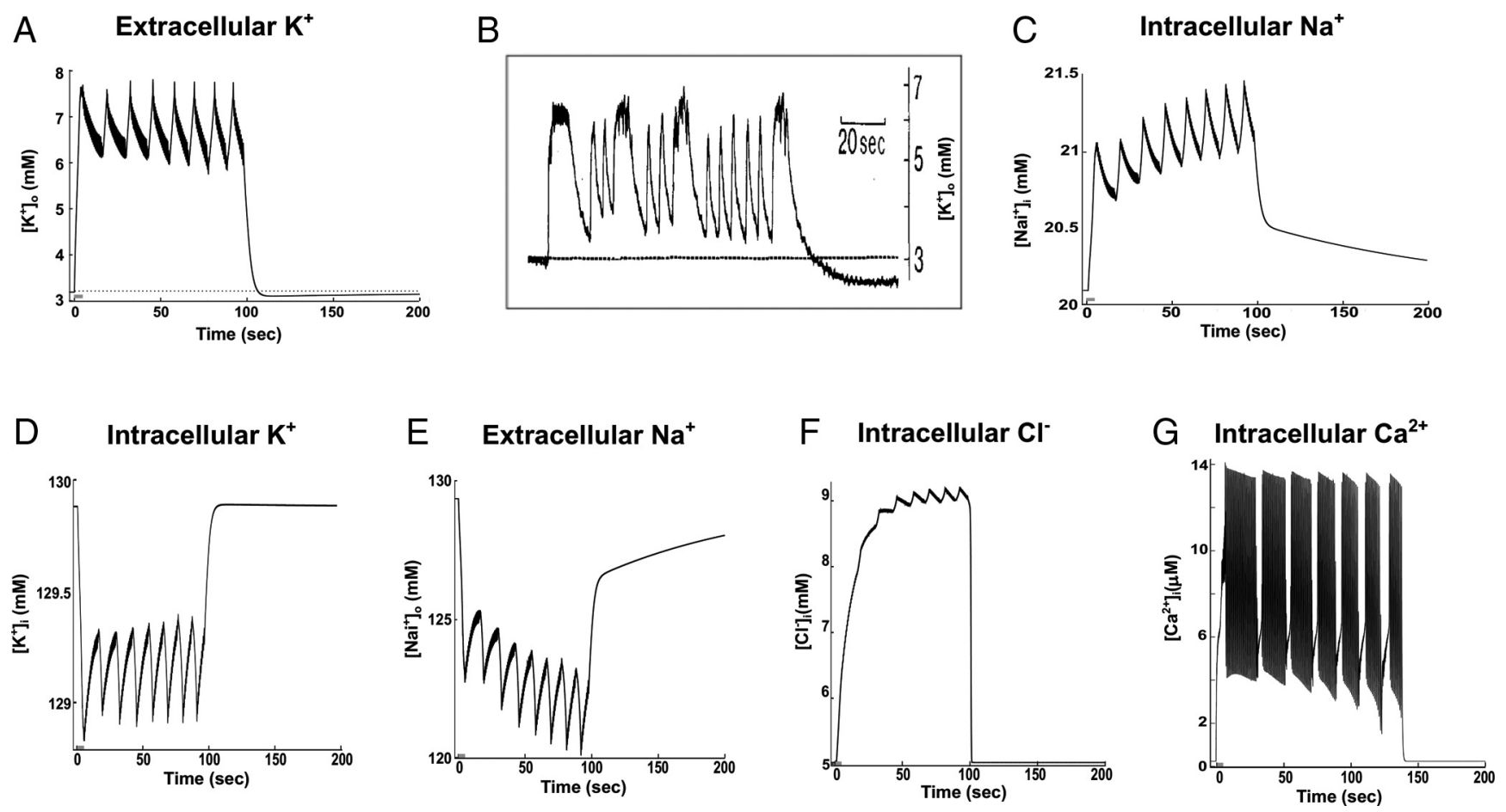

Figure 3. Ionic concentrations dynamics over the course of seizure. Data correspond to the simulation shown in the Figure $2 . A_{,}\left[\mathrm{K}^{+}\right]_{0}$ in the extracellular space of one pyramidal neuron increased during tonic states and decreased during bursting. $\left[\mathrm{K}^{+}\right]_{0}$ reduced below baseline (dashed line) immediately after seizure termination. $\boldsymbol{B}$, In vivo $\left[\mathrm{K}^{+}\right]_{0}$ dynamics during epileptic seizure shows similar oscillations and decay below baseline after termination of seizure (Heinemann et al., 1977). $\mathbf{C}-\mathbf{G}$, Dynamics of $\left.\left[\mathrm{Na}^{+}\right]_{\mathrm{i}}{ }^{\prime} \mathrm{K}^{+}\right]_{\mathrm{i}}\left[\mathrm{Na}^{+}\right]_{\mathrm{o}^{\prime}}\left[\mathrm{Cl}^{-}\right]_{\mathrm{i}}$, and $\left[\mathrm{Ca}^{2+}\right]_{\mathrm{i}}$ during epileptic seizure-like activity. Both $\left[\mathrm{Na}^{+}\right]_{\mathrm{i}}$ and $\left[\mathrm{Cl}^{-}\right]_{\mathrm{i}}$ increased progressively until termination of seizure. $\left[\mathrm{Ca}^{2+}\right]_{\mathrm{i}}$ shows large-amplitude oscillations during bursting and remains relatively low during tonic spiking.

phase of the network activity. This was a result of the higher frequency of cell firing in the network and explained progressive $\left[\mathrm{Na}^{+}\right]_{\mathrm{i}}$ accumulation during seizure. The $\left[\mathrm{Cl}^{-}\right]_{\mathrm{i}}$ increased primarily at the early stage of seizure within the first $50 \mathrm{~s}$, and later maintained a steady range of values $\sim 9 \mathrm{~mm}$ (Fig. $3 F$ ) in agreement with experimental observations, showing elevation of $\mathrm{GABA}_{\mathrm{A}}$ reversal potential during the early stage of seizure (Timofeev et al., 2002). The increase of $\left[\mathrm{Cl}^{-}\right]_{i}$ was attributable to the leak $\mathrm{Cl}^{-}$currents, activation of $\mathrm{GABA}_{\mathrm{A}}$ conductances, and reduction of KCC2 pump efficacy in conditions of elevated $\left[\mathrm{K}^{+}\right]_{\mathrm{o}}$. Since in normal physiological conditions, the extracellular $\mathrm{Cl}^{-}$concentration is much higher than the intracellular one, we assumed in the model an infinite pool of extracellular $\mathrm{Cl}^{-}$ with constant concentration. The $\left[\mathrm{Na}^{+}\right]_{\mathrm{o}}$ and $\left[\mathrm{K}^{+}\right]_{\mathrm{i}}$ showed changes opposite to their corresponding concentrations on the other side of the membrane. Progressive increase of the mean level of $\left[\mathrm{Na}^{+}\right]_{\mathrm{i}}$ over the entire course of seizure suggests that this may be a primary factor mediating termination of epileptiform activity in our model. Possible role of $\left[\mathrm{Na}^{+}\right]_{\mathrm{i}}$ dynamics in shaping bursts of action potentials was previously shown using a simplified neuronal model in the study by Cressman et al. (2009). In the next section, we will apply bifurcation analysis to reveal the specific role of $\left[\mathrm{Na}^{+}\right]_{\mathrm{i}}$ in terminating paroxysmal states. Furthermore, we will show that changing $\left[\mathrm{Na}^{+}\right]_{i}$ dynamics to slow down $\left[\mathrm{Na}^{+}\right]_{\mathrm{i}}$ accumulation during seizure significantly extended seizure duration (see Fig. 6B).

After seizure termination, $\left[\mathrm{Na}^{+}\right]_{i}$ remained elevated before returning to the baseline several seconds later. Since elevation of $\left[\mathrm{Na}^{+}\right]_{\mathrm{i}}$ above baseline leads to stronger activation of $\mathrm{Na}^{+} / \mathrm{K}^{+}$ exchange pump, this $\left[\mathrm{Na}^{+}\right]_{\mathrm{i}}$ dynamics mediated decrease of $\left[\mathrm{K}^{+}\right]_{\mathrm{o}}$ below baseline after termination of paroxysmal activity (Fig. $3 A$ ) and may explain experimental observations of undershooting $\left[\mathrm{K}^{+}\right]_{\mathrm{o}}$ level after seizures (Fig. 3B).

\section{Bifurcation analysis explains mechanisms of seizure} termination

To understand how changes in ion concentrations may lead to the termination of seizure, a reduced model of a single pyramidal neuron with all ion concentrations fixed was studied. Since ion concentration changes were much slower in our model than dynamics of membrane voltage or the gating variables of intrinsic currents, we used fast-slow decomposition analysis (Rinzel and Ermentrout, 1989) assuming all the ion concentrations to be fixed model parameters. With this "open-loop" method (Fröhlich et al., 2008), the modulation of ionic concentrations by neural activity was artificially removed. By choosing different values for ion concentrations, the corresponding neuronal activity patterns for each set of ion concentrations can be determined ("open loop" dynamics). Thus, the neuron activity was computed for a given fixed set of values of all ion concentrations, and we explored how neuronal dynamics depend on changes in ion concentrations. The neuron dynamics were categorized into resting, spiking/bursting, and depolarization block state for each set of ion concentrations. The resting state of the neuron corresponded to the stable equilibrium of the model. [If neuron dynamics is described by a set of equations, $d X / d t=F(X)$, where $X$ is a vector representing all dynamical variables of the model, then equilibria (or fixed points) are defined as the values of $X$ where $F(X)=0$ ]. A stable equilibrium represents stable resting state of the neuron if any small perturbations (e.g., small transient current injections) decay in time and neuron returns to the resting state. As the model parameters (e.g., ion concentrations) change, the stable equilibrium may become unstable at so-called bifurcation points (these points represent critical values of the model parameters when model dynamics changes); the latter may correspond to transitions to the spiking activity (Fröhlich and Bazhenov, 2006; Izhikevich, 2006; Cressman et al., 2009). Here, we 
used bifurcation analysis (or numerical continuation) (Kuznetsov, 1995) to identify transitions between different neuron states as we changed ion concentration parameters.

We first changed $\left[\mathrm{K}^{+}\right]_{\mathrm{o}}$ and kept other ion concentrations fixed: $\left[\mathrm{Na}^{+}\right]_{\mathrm{i}}=20$ $\mathrm{mM},\left[\mathrm{Na}^{+}\right]_{\mathrm{o}}=130 \mathrm{mM},\left[\mathrm{K}^{+}\right]_{\mathrm{i}}=130 \mathrm{~mm}$, and $\left[\mathrm{Cl}^{-}\right]_{\mathrm{i}}=5 \mathrm{~mm}$. Figure $4 \mathrm{~A}$ shows membrane voltage at equilibrium (resting state of the neuron) for various values of $\left[\mathrm{K}^{+}\right]_{\mathrm{o}}$. A set of stable equilibria representing stable resting states was identified for $\left[\mathrm{K}^{+}\right]_{\mathrm{o}}$ between 0 and $5.34 \mathrm{~mm}$. The resting state of the neuron lost stability by a saddle-node bifurcation (SN) (Kuznetsov, 1995) at $\left[\mathrm{K}^{+}\right]_{\mathrm{o}}=5.34 \mathrm{~mm}$. This corresponded to transition to the spiking activity. For values of $\left[\mathrm{K}^{+}\right]_{\mathrm{o}}>5.34 \mathrm{~mm}$, the silent state was unstable and the neuron demonstrated various types of spiking firing patterns. Another bifurcation point was detected at $\left[\mathrm{K}^{+}\right]_{\mathrm{o}}=11.42 \mathrm{~mm}$. The silent state of the neuron became stable again for values of $\left[\mathrm{K}^{+}\right]_{\mathrm{o}}>11.42 \mathrm{~mm}$. The bifurcation at $\left[\mathrm{K}^{+}\right]_{\mathrm{o}}=11.42 \mathrm{~mm}$ was identified to be Andronov-Hopf (AH) bifurcation (Kuznetsov, 1995). This bifurcation corresponded to transition to another silent state of the model neuron corresponding to depolarization block when membrane voltage was locked at a relatively elevated level $(-29.67 \mathrm{mV})$. This state is commonly observed during epileptic seizures (Ziburkus et al., 2006).

In the previous analysis, $\left[\mathrm{K}^{+}\right]_{\mathrm{o}}$ was varied as a sole bifurcation parameter (Fig. $4 A$, left), and we found critical values of $\left[\mathrm{K}^{+}\right]_{\mathrm{o}}$ corresponding to transitions from silent to active spiking states for a fixed combination of other ion concentrations $\left(\left[\mathrm{Na}^{+}\right]_{\mathrm{i}}=20 \mathrm{~mm},\left[\mathrm{Na}^{+}\right]_{\mathrm{o}}=130\right.$ $\mathrm{mM},\left[\mathrm{K}^{+}\right]_{\mathrm{i}}=130 \mathrm{~mm}$, and $\left[\mathrm{Cl}^{-}\right]_{\mathrm{i}}=5$ $\mathrm{mm})$. The bifurcation analysis was then extended to include two other ion concentrations $\left(\left[\mathrm{Na}^{+}\right]_{\mathrm{i}}\right.$ and $\left.\left[\mathrm{Cl}^{-}\right]_{\mathrm{i}}\right)$. Corresponding two-parametric bifurcation diagrams were plotted in Figure $4 A$, middle and right panels. In these diagrams, the critical values of $\left[\mathrm{K}^{+}\right]_{\mathrm{o}}$ corresponding transitions between silent and spiking states ( $\mathrm{SN}$ bifurcation points) and between spiking and depolarization block states (AH bifurcation points) were traced for varying concentrations of $\left[\mathrm{Na}^{+}\right]_{\mathrm{i}}$ (Fig. $4 A$, middle) and $\left[\mathrm{Cl}^{-}\right]_{\mathrm{i}}$ (Fig. $4 A$, right). Increasing the $\left[\mathrm{Na}^{+}\right]_{\mathrm{i}}$ moved the $\mathrm{SN}$ bifurcation point toward higher values of $\left[\mathrm{K}^{+}\right]_{\mathrm{o}}$; at around $\left[\mathrm{Na}^{+}\right]_{\mathrm{i}}$ $=23 \mathrm{~mm}$, the SN point overlapped with the $\mathrm{AH}$ point (Fig. $4 \mathrm{~A}$, middle). For $\left[\mathrm{Na}^{+}\right]_{\mathrm{i}}$ beyond this point, the neuron remained silent (either at rest or in depolarization block) for any values of $\left[\mathrm{K}^{+}\right]_{\mathrm{O}}$. The shift of the SN bifurcation point to the higher values of $\left[\mathrm{K}^{+}\right]_{\mathrm{o}}$ with increase in $\left[\mathrm{Na}^{+}\right]_{\mathrm{i}}$ corresponded to increase of the minimal $\left[\mathrm{K}^{+}\right]_{\mathrm{o}}$ level at which the neuron transitioned from resting state to spiking activity. In contrast, increase of $\left[\mathrm{Cl}^{-}\right]_{\mathrm{i}}$ resulted in the SN point shifting toward lower values of $\left[\mathrm{K}^{+}\right]_{\mathrm{o}}$ (Fig. $4 A$, right). This corresponded to earlier transition to spiking.
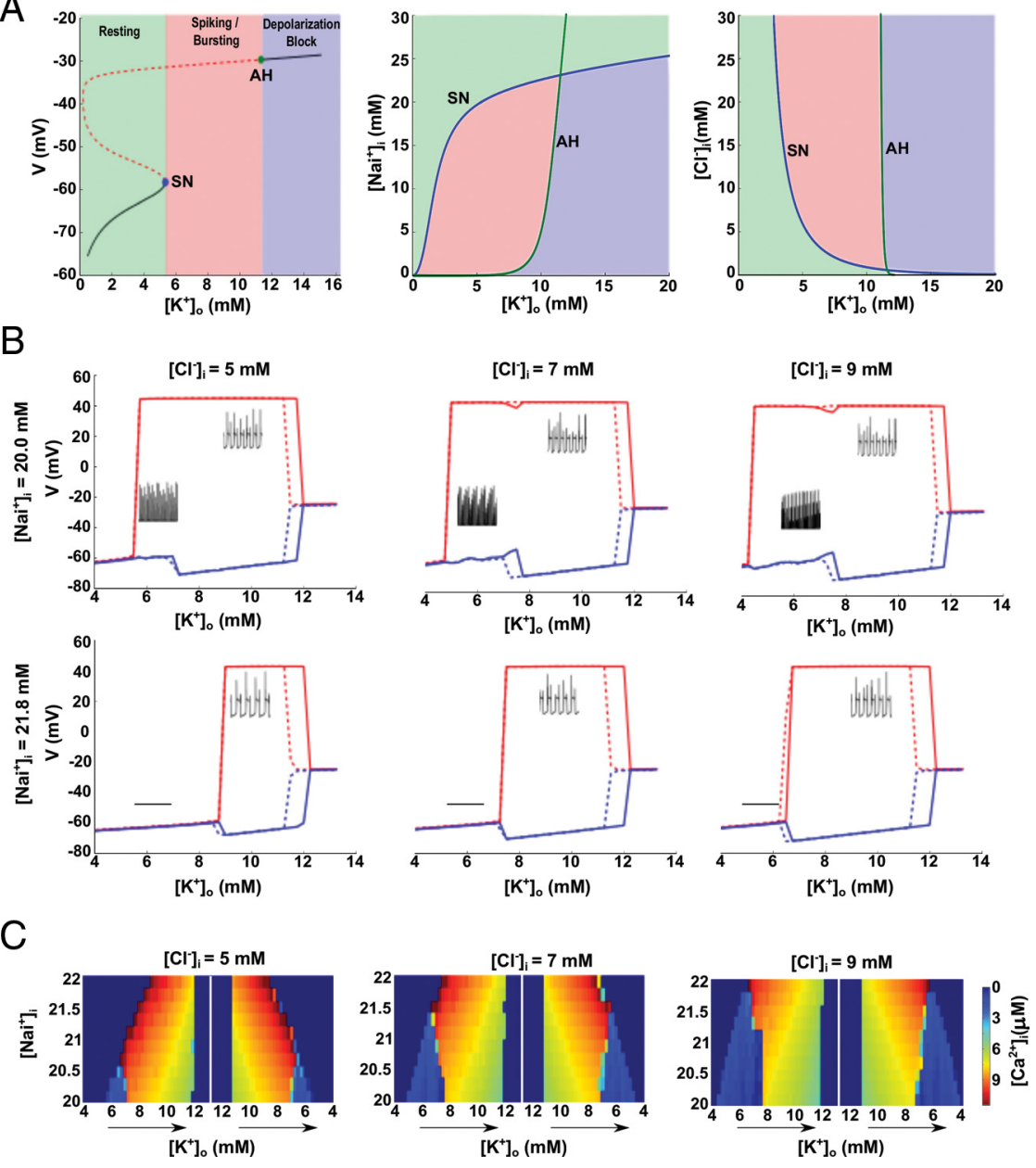
a foltage is plotted against parameter $\left[\mathrm{K}^{+}\right]_{0}$ ). Transitions between stable (solid line) unstable (dashed line) attractors occurred at the SN and the AH bifurcation points. Middle and right, Two parametric的 $\left.]_{\mathrm{i}}\right)$ in the middle and $\left(\left[\mathrm{K}^{+}\right]_{0^{\prime}}\left[\mathrm{Cl}^{-}\right]_{\mathrm{i}}\right)$ on the right- bifurcation plots. SN and AH lines indicate bifurcation curves plotted as a function of parameter $\left[\mathrm{K}^{+}\right]_{0}$. Each plot was obtained under different fixed values for $\left[\mathrm{Na}^{+}\right]_{\mathrm{i}}$ and $\left[\mathrm{Cl}^{-}\right]_{\mathrm{i}}$. All other ionic concentrations remained fixed. The insets show sample voltage traces for two values of $\left[\mathrm{K}^{+}\right]_{0}(6.1$ and $9.5 \mathrm{~mm})$. $C$, Amplitude of $\left[\mathrm{Ca}^{2+}\right]_{\mathrm{i}}$ oscillations plotted in the plane of $\left[\mathrm{K}^{+}\right]_{0}$ and $\left[\mathrm{Na}^{+}\right]_{\mathrm{i}}$. Separate plots correspond to different $\left[\mathrm{Cl}^{-}\right]_{\mathrm{i}}$ values. Each plot was obtained for progressively increasing (left) and then decreasing (right) values of $\left[\mathrm{K}^{+}\right]_{0}$. The arrows point the direction of $\left[\mathrm{K}^{+}\right]$ change. The asymmetry in the image (more prominent for high $\left[\mathrm{Cl}^{-}\right]_{\mathrm{i}}$ ) indicates hysteresis because of bistability in the model. The dark blue color corresponds to the silent state of the neuron. Light blue, Tonic spiking. Purple/yellow, Bursting. Note expansion of the tonic spiking region for higher $\left[\mathrm{Cl}^{-}\right]_{\mathrm{i}}$ values. Tonic spiking region disappeared for sufficiently large values of $\left[\mathrm{Na}{ }^{+}\right]_{\mathrm{i}}$.

Together, these results suggest that changing of $\left[\mathrm{Na}^{+}\right]_{\mathrm{i}}$ or $\left[\mathrm{Cl}^{-}\right]_{\mathrm{i}}$ significantly affect minimal $\left[\mathrm{K}^{+}\right]_{\mathrm{o}}$ level that is required for transition to spiking and it can potentially make transition to paroxysmal state impossible.

To further illustrate how ion concentrations may affect neuronal activity during seizure, we analyzed dynamics of a single pyramidal neuron as a function of selected ion concentrations. Figure $4 B$ shows minimum and maximum values of membrane voltage of one pyramidal neuron for different combinations of $\left[\mathrm{K}^{+}\right]_{\mathrm{o}}$ and $\left[\mathrm{Na}^{+}\right]_{\mathrm{i}}$. In this type of analysis, existence of only one value of membrane voltage indicates nonoscillatory state (either at rest or in depolarization block). Oscillations are represented by two voltage values (maximum and minimum). Finally, tonic spiking and bursting states can be separated by analyzing minima of membrane voltage-more negative minima correspond to bursting. Alternatively, we plotted $\left[\mathrm{Ca}^{2+}\right]_{\mathrm{i}}$ level (Fig. $4 C$ ); since accumulation of $\left[\mathrm{Ca}^{2+}\right]_{i}$ was significantly higher in burst- 
A

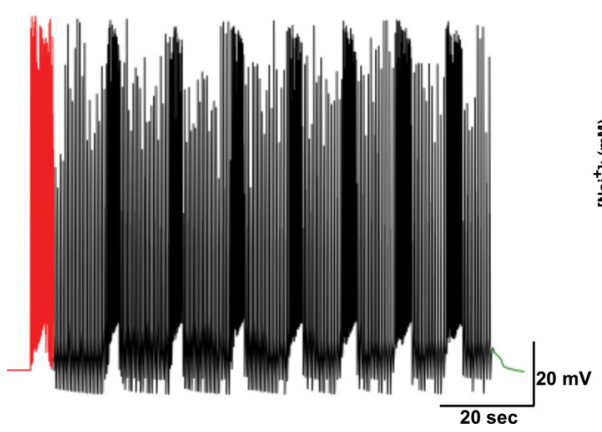

B

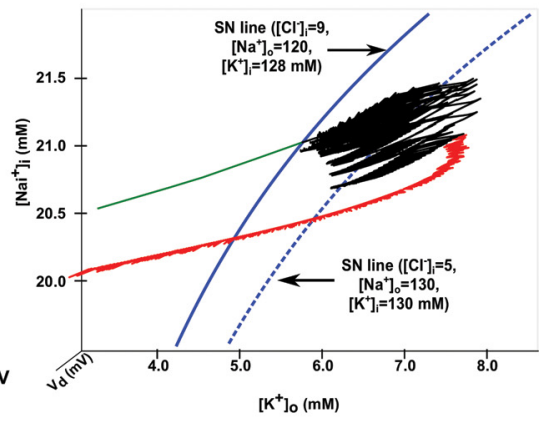

Figure 5. Dynamics of the epileptic activity in the model state space. $A$, Membrane voltage trace of a pyramidal neuron from small network (10 PY-2 IN). Different colors indicate different episodes of seizure. $\boldsymbol{B}$, Top view of activity of pyramidal neuron in three-dimensional space of $\left[\mathrm{K}^{+}\right]_{0},\left[\mathrm{Na}^{+}\right]_{\mathrm{i}}$, and membrane voltage, along with lines of bifurcation boundaries indicating transition from resting state to spiking. The dashed blue line indicates bifurcation boundary for $\left[\mathrm{Cl}^{-}\right]_{\mathrm{i}}=5 \mathrm{~mm},\left[\mathrm{Na}^{+}\right]_{0}=130 \mathrm{~mm}$, $\left[\mathrm{K}^{+}\right]_{\mathrm{i}}=130 \mathrm{~mm}$ (conditions similar to the resting state). The solid blue line indicates bifurcation boundary for $\left[\mathrm{Cl}^{-}\right]_{\mathrm{i}}=9 \mathrm{~mm}$, $\left[\mathrm{Na}^{+}\right]_{0}=120 \mathrm{~mm}$, and $\left[\mathrm{K}^{+}\right]_{\mathrm{i}}=128 \mathrm{~mm}$ (conditions similar to termination of seizure in the network).

ing state versus tonic spiking (Figs. $3 G, 4 C$ ), we could use it to differentiate between these network states. To reveal bistability (i.e., coexistence of different dynamical states for the same range of $\left[\mathrm{K}^{+}\right]_{\mathrm{o}}$ ), we conducted analyses for progressively increasing and decreasing values of $\left[\mathrm{K}^{+}\right]_{\mathrm{o}}$, always starting from initial conditions from the previous simulation (Fig. $4 B$, solid and dashed lines; $C$, left and right half of each panel). We found that transitions between different network states occurred at different values of $\left[\mathrm{K}^{+}\right]_{\mathrm{o}}$ based on direction (increase or decrease) of $\left[\mathrm{K}^{+}\right]_{\mathrm{o}}$ change; this indicates hysteresis arising because of bistability (see, e.g., range of $\left[\mathrm{K}^{+}\right]_{\mathrm{o}}$ between 7.6 and $7.9 \mathrm{~mm}$ in Fig. $4 B$, middle/top). The existence of bistability leading to hysteresis was shown in our previous studies (Fröhlich and Bazhenov, 2006; Fröhlich et al., 2006). However, our new model revealed that (1) an increase in $\left[\mathrm{Na}^{+}\right]_{\mathrm{i}}$ reduced the range of $\left[\mathrm{K}^{+}\right]_{\mathrm{o}}$ where tonic spiking regimen was possible (Fig. $4 \mathrm{~B}$, compare top and bottom plots; $C$, light blue region). It also eliminated bistability, so transitions between silent and bursting states occurred for the same level of $\left[\mathrm{K}^{+}\right]_{\mathrm{o}}$ regardless of the direction of $\left[\mathrm{K}^{+}\right]_{\mathrm{o}}$ change. (2) An increase of $\left[\mathrm{Cl}^{-}\right]_{\mathrm{i}}$ had an opposite effect, expanding tonic spiking range and also increasing region of bistability (range of $\left[\mathrm{K}^{+}\right]_{\mathrm{o}}$ ) between tonic spiking and bursting.

This study shows that increase of $\left[\mathrm{Na}^{+}\right]_{\mathrm{i}}$ makes neurons stay in resting state at values of $\left[\mathrm{K}^{+}\right]_{0}$ that would otherwise (for lower values of $\left[\mathrm{Na}^{+}\right]_{\mathrm{i}}$ ) result in tonic spiking activity. It suggests that a slow increase of $\left[\mathrm{Na}^{+}\right]_{i}$ during seizure can lead to the disappearance of bistability required for self-sustained periodic transitions between tonic spiking and bursting and could result in termination of paroxysmal activity. In other words, during late phase of seizure when $\left[\mathrm{Na}^{+}\right]_{\mathrm{i}}$ is sufficiently elevated, a progressive decrease of $\left[\mathrm{K}^{+}\right]_{0}$ that would normally lead to transition to tonic spiking starting a new cycle of oscillations, would result in transition to silent state and termination of seizure.

To further elucidate the role of $\left[\mathrm{Na}^{+}\right]_{\mathrm{i}}$ on seizure termination, we again allowed all the ion concentrations to evolve freely according to the model equations. This corresponds to "closeloop" dynamics (Fröhlich et al., 2008) with all the ion concentration being updated based on the neuronal activity rather than being fixed as we did in the bifurcation analysis on the Figure 4 . The entire episode of seizure was plotted in the state space of the neuron model along with the bifurcation points. Figure $5 B$ shows the state trajectory in the space of $\left[\mathrm{K}^{+}\right]_{\mathrm{o}}$ and $\left[\mathrm{Na}^{+}\right]_{\mathrm{i}}$ corresponding to the membrane voltage evolution during episode of seizure presented in the Figure $5 A$. The blue lines in Figure $5 B$ indicate $\mathrm{SN}$ bifurcation points (critical values of $\left[\mathrm{K}^{+}\right]_{\mathrm{o}}$ for different values of $\left[\mathrm{Na}^{+}\right]_{\mathrm{i}}$ corresponding to transition from silence to tonic spiking) obtained for two different levels of $\left[\mathrm{Cl}^{-}\right]_{\mathrm{i}}$ (9 and $5 \mathrm{~mm}$ ) as described above. This analysis revealed that seizure was initiated once the initial transient stimulation (Fig. 5 , red portion of trajectory) forced the state trajectory to cross the curve of $\mathrm{SN}$ points and to move beyond a critical value of $\left[\mathrm{K}^{+}\right]_{\mathrm{o}}$ corresponding to the left boundary of the bistability region between tonic and bursting modes. This initiated selfsustained activity and the state trajectory stayed in the region of $\left[\mathrm{K}^{+}\right]_{\mathrm{o}}$ that corresponded to slow transitions between tonic spiking and bursting (black portion of trajectory). Epileptic activity was accompanied by progressive increase of $\left[\mathrm{Na}^{+}\right]_{\mathrm{i}}$ and $\left[\mathrm{Cl}^{-}\right]_{\mathrm{i}}$. The $\left[\mathrm{Na}^{+}\right]_{\mathrm{i}}$ increase tended to move state trajectory to the left; the seizure would terminate once trajectory crosses the SN bifurcation boundary. However, increase in $\left[\mathrm{Cl}^{-}\right]_{\mathrm{i}}$ moved the SN boundary to the left, causing the trajectory to stay in the oscillatory state longer. Nevertheless, once the $\left[\mathrm{Na}^{+}\right]_{\mathrm{i}}$ reached a high enough value, the trajectory again crossed the $\mathrm{SN}$ bifurcation boundary. At this point, the silent state became stable (green portion of trajectory), which corresponded to seizure termination. This analysis concisely describes the course of seizure and provides additional evidence that $\left[\mathrm{Na}^{+}\right]_{\mathrm{i}}$ increase leads to termination of seizure.

\section{Seizure duration depends on synaptic connectivity and chloride buildup}

Our analysis (Figs. 4, 5) suggests that duration of seizure may depend on the speed of $\left[\mathrm{Cl}^{-}\right]_{\mathrm{i}}$ buildup that itself depends on the strength of the cation-chloride channel KCC2 pump. In normal physiological conditions, the KCC2 pump uses the difference in $\left[\mathrm{K}^{+}\right]$across the membrane to maintain a low level of $\left[\mathrm{Cl}^{-}\right]_{\mathrm{i}}$ at $\sim 5$ mm (Payne et al., 2003). In our model, the $\left[\mathrm{Cl}^{-}\right]_{\mathrm{i}}$ rapidly increased during the early stage of seizure (Fig. 3), similar to results of experimental studies (Timofeev et al., 2002). This increase in $\left[\mathrm{Cl}^{-}\right]_{\mathrm{i}}$ partly resulted from reduction of KCC2 pump efficacy in conditions of elevated $\left[\mathrm{K}^{+}\right]_{\mathrm{o}}$.

Increase of $\left[\mathrm{Cl}^{-}\right]_{\mathrm{i}}$ was crucial for sustaining paroxysmal activity. The range of $\left[\mathrm{K}^{+}\right]_{\mathrm{o}}$ in which the neuron was able to maintain hysteresis between tonic spiking and bursting was extended in conditions of elevated $\left[\mathrm{Cl}^{-}\right]_{\mathrm{i}}$, which significantly extended duration of seizure (Figs. 4B,5). To directly test the role of KCC2 pump efficacy on seizure duration, we reduced the time constant of KCC2 pump (Fig. 6A). As a result, pump performance was less affected by extracellular potassium concentration, leading to slower $\left[\mathrm{Cl}^{-}\right]_{\mathrm{i}}$ buildup; this decreased seizure duration and could even prevent initiation of seizure for the same strength of external DC stimulation. When KCC2 pump time constant was small, paroxysmal activity terminated almost immediately after offset of DC stimulation, even though $\left[\mathrm{K}^{+}\right]_{0}$ still reached high levels (Fig. $6 \mathrm{~A}$ ). In contrast, increasing KCC2 pump time constant allowed $\left[\mathrm{Cl}^{-}\right]_{\mathrm{i}}$ to rise higher and led to longer seizures.

According to our hypothesis, progressive increase of $\left[\mathrm{Na}^{+}\right]_{\mathrm{i}}$ over the course of seizure leads to its termination. If correct, this would suggest that changing the rate of $\left[\mathrm{Na}^{+}\right]_{\mathrm{i}}$ accumulation 
would affect seizure duration. Below, we tested this prediction. Since action potentials are one of the main sources of $\left[\mathrm{Na}^{+}\right]_{\mathrm{i}}$ increase during active states in our model, we artificially slowed down accumulation of $\left[\mathrm{Na}^{+}\right]_{\mathrm{i}}$ by decreasing the amount of $\mathrm{Na}^{+}$ions entering the cell during each action potential. This was done without changing voltage-gated $\mathrm{Na}^{+}$conductance itself and therefore without affecting spiking dynamics. Indeed, we found that slower accumulation of $\left[\mathrm{Na}^{+}\right]_{\mathrm{i}}$ significantly extended seizure duration (Fig. $6 B)$. When $\left[\mathrm{Na}^{+}\right]_{\mathrm{i}}$ remained low, the paroxysmal state never ended for even very long simulations (Fig. $6 \mathrm{~B}$, left, three leftmost data points). In contrast, when $\mathrm{Na}^{+}$ contribution from action potentials was high, we could not initiate self-sustained seizure and network activity terminated almost immediately after stimulus offset.

Duration of seizure also depended on the strength of excitatory and inhibitory connections. In the model of 10 pyramidal cells and 2 inhibitory interneurons, selfsustained seizure was absent for low values of PY-PY (AMPA) and IN-PY $\left(\mathrm{GABA}_{\mathrm{A}}\right)$ connections (Fig. $6 C$ ). In this case, the network model behaved similar to an isolated neuron. There was, however, one important difference. Even with all synaptic connections blocked, the neurons within a network could communicate by means of ion diffusion between extracellular compartments associated with individual neurons. As a result, when strength of initial DC stimulation was increased, it led to short episodes of seizure-like activity (data not shown). The seizure duration depended on both excitatory (PY-PY) and inhibitory (IN-PY) connections; removing either excitation or inhibition reduced seizure duration (Fig. $6 C$, left). For high values of PY-PY and IN-PY connection strength, seizure-like activity lasted continuously. The relative strength of PY-PY and IN-PY connections also determined the dominant state in which neurons stayed during seizure. Increase in both PY-PY and IN-PY connection strength led to longer burst duration (Fig. $6 C$, right). Since $\left[\mathrm{Na}^{+}\right]_{\mathrm{i}}$ level remained relatively low in bursting mode, it was not sufficient to promote termination of seizure when the model burst continuously, which explains continuous oscillations for high synaptic strength.

\section{Below baseline reduction of the extracellular potassium mediates postictal depression state}

The network model described in the previous sections included only 10 excitatory pyramidal neurons and 2 inhibitory interneurons. To test whether our results can be generalized to larger networks, we simulated a model including $100 \mathrm{PY}$ and $20 \mathrm{IN}$ cells. To make simulations more realistic, we also included background noise that was modeled as Poisson-distributed spike
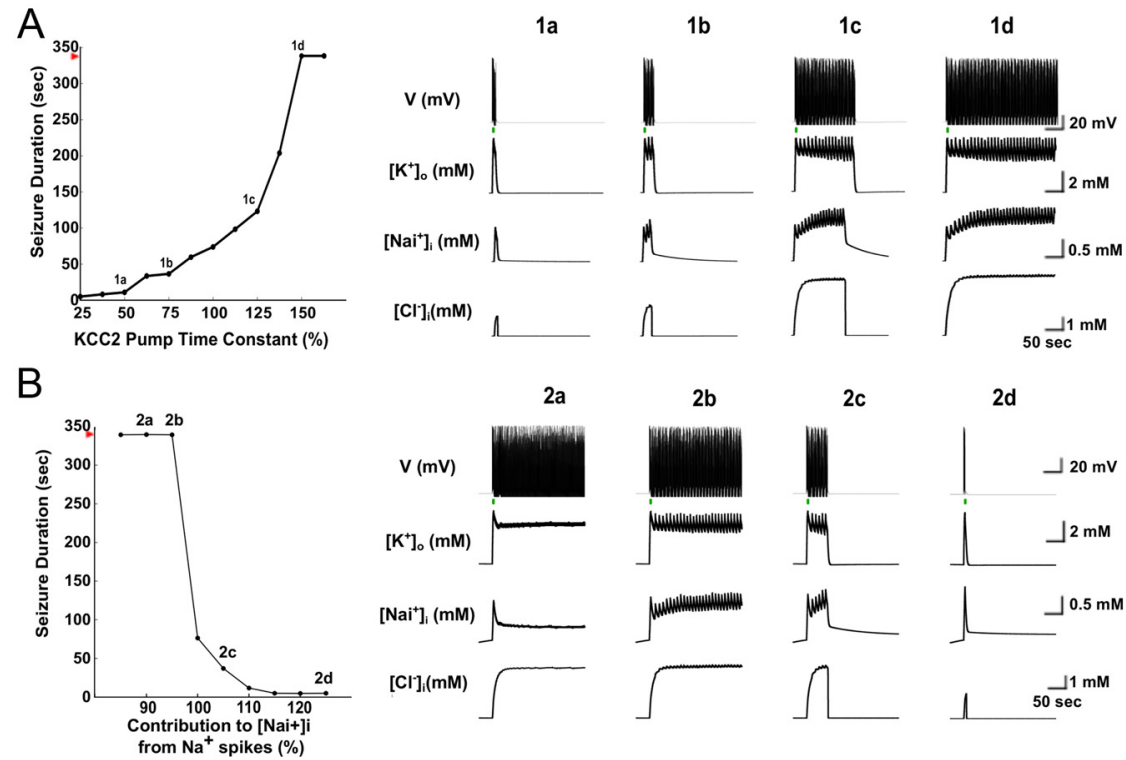

$2 d$

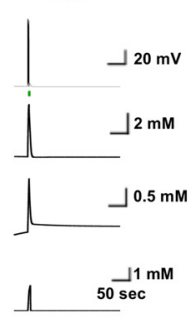

Ratio (Bursting/Tonic-Clonic Period)
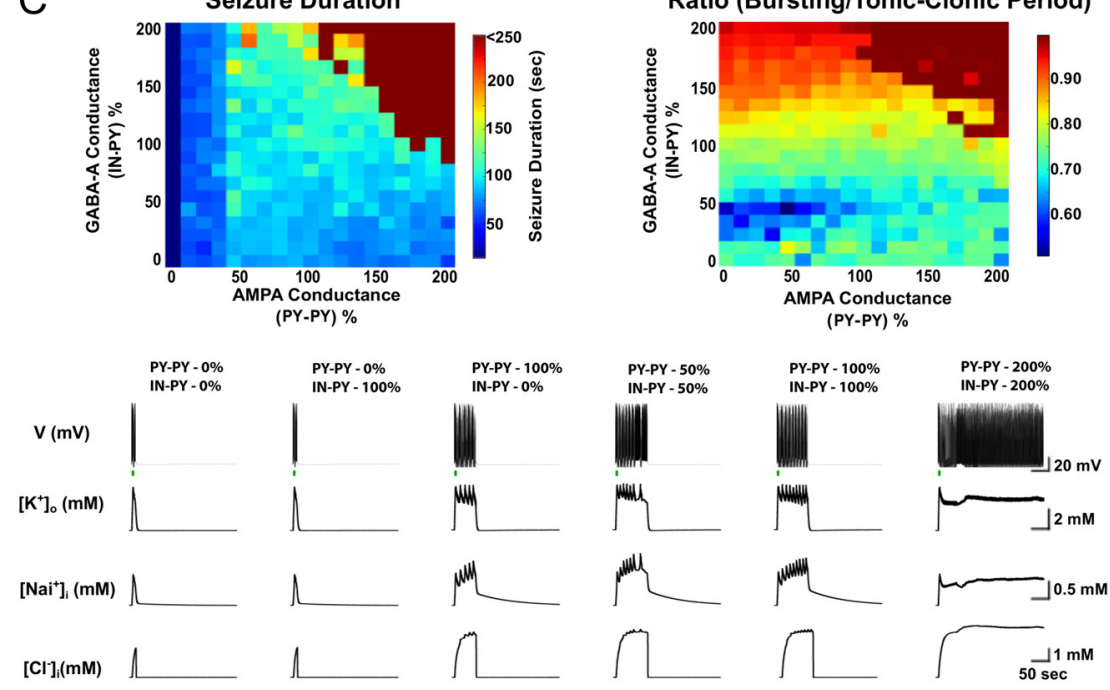

Figure 6. Effect of $\mathrm{KCC} 2$ pump and rate of $\left[\mathrm{Na}^{+}\right]_{\mathrm{i}}$ buildup on seizure duration. $A$, Plot shows the seizure duration as a function and ${ }_{0}$ and $\left[\mathrm{Na}^{+}\right]_{\mathrm{i}}$ traces. $\boldsymbol{B}$, Plot shows the seizure duration as a function of the rate of $\left[\mathrm{Na}^{+}\right]_{\mathrm{i}}$ buildup. The last was varied by changing the contribution to $\left[\mathrm{Na}^{+}\right]_{i}$ from activity of the voltage-gated fast $\mathrm{Na}^{+}$channels mediating the action potentials. the plots on the bottom show the activity of a single neuron and corresponding $\left[\mathrm{K}^{+}\right]_{0}$ and $\left[\mathrm{Na}^{+}\right]$ traces. Stimulus duration was identical in all experiments as indicated by the green bar.

trains delivered through AMPA-type synapses to all neurons in the network. To account for homeostatic changes found experimentally in the neurons driven by external noise, we increased slightly conductance of the $\left[\mathrm{K}^{+}\right]$leak current, as seen in the study by van Welie et al. (2006), reduced conductances for high threshold $\left[\mathrm{Ca}^{2+}\right]$ (O'Leary et al., 2010) and fast sodium currents (Grubb and Burrone, 2010), and increased conductance for $\mathrm{Cl}^{-}$ leak current (see Materials and Methods). With these changes, the network was stable and displayed spontaneous random spiking activity at a mean rate of $0.5 \mathrm{~Hz}$ (Fig. 7).

The mean frequency of the external Poisson input was transiently increased from 140 to $400 \mathrm{~Hz}$ for $2 \mathrm{~s}$ (Fig. 7B, red bar). This initiated seizure-like oscillations, which included sequences of bursting and tonic spiking episodes lasting for $\sim 200$ s total. Sim- 

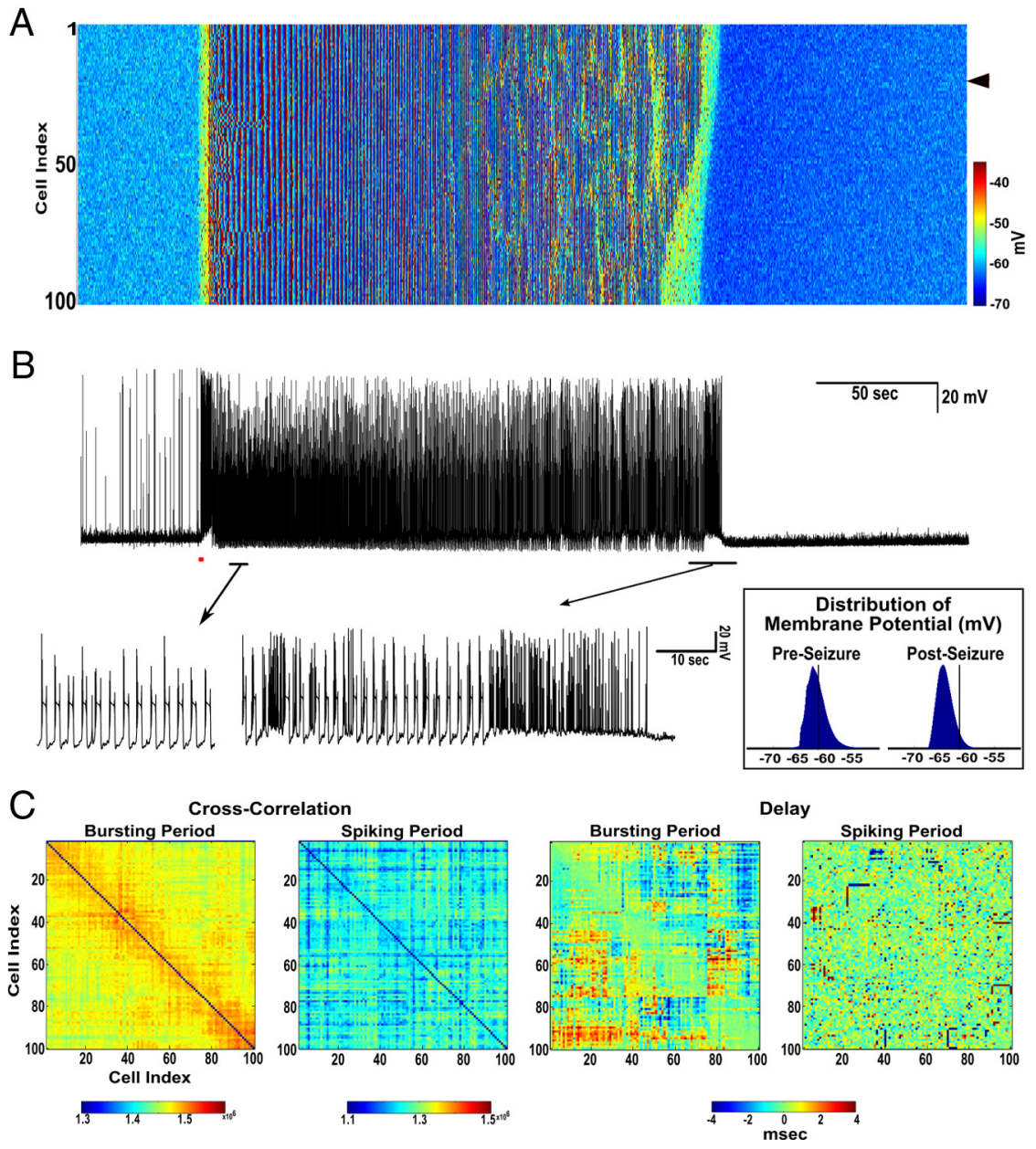

Figure 7. Seizure termination in a large network with noise and postictal depression. $\boldsymbol{A}$, Space-time plot of activity of 100 pyramidal neurons from a network over time. The red bar indicates transient increase of the external Poisson rate. $\boldsymbol{B}$, Activity of a single pyramidal neuron includes episodes of baseline low-frequency spiking before stimulation $(\boldsymbol{a})$, self-sustained seizure-like oscillations including slow bursting and tonic firing (see expanded plots) (b), and period of postictal depression after termination of paroxysmal activity (c). Inset, Distribution of membrane potential from all cells before the onset of seizure and in postictal state. C, Left, Peaks of cross-correlation computed between all pairs of pyramidal neurons for bursting and spiking periods. Right, Delays corresponding to the peak of cross-correlation for all pairs of pyramidal neurons.

ilar to smaller networks (Fig. 2), this larger network displayed a high level of synchrony across the entire population of neurons during bursting episodes and reduced synchrony during tonic spiking (Fig. 7A). Bursting episodes were primarily found during earlier phases of epileptiform activity and were interrupted by epochs of fast runs during later phases of the seizure (Fig. $7 B$ ). To quantify the change in synchronization, cross-correlation was computed between all pairs of pyramidal neurons separately for bursting and spiking periods. Bursting periods were identified as the periods when membrane potential was consecutively above $-20 \mathrm{mV}$ for $>200 \mathrm{~ms}$; spiking periods were identified as consecutive $500 \mathrm{~ms}$ periods with firing rate $>10 \mathrm{~Hz}$ when there was no bursting. Cross-correlation was higher during bursting periods compared with spiking periods (Fig. $7 C$ ), with the nearby cells showing highest cross-correlation as seen by increase in the values near the diagonal in Figure $7 C$ (left). Distribution of delays to the main peak of the cross-correlation function suggests formation of clusters during bursting periods while spiking periods showed random pattern of delays (Fig. $7 C$, right).

To initiate self-sustained paroxysmal oscillations, transient increase of the Poisson input had to exceed certain minimal level sug- gesting existence of the threshold for seizure initiation as we previously reported (Fröhlich et al., 2010). Indeed, small perturbations only led to short transient firing rate increase followed by return to the baseline firing, therefore indicating stability of the physiological (random spiking) state in our model including dynamics of different ion concentrations.

Concentration of sodium, $\left[\mathrm{Na}^{+}\right]_{\mathrm{i}}$, increased progressively during seizure, reaching it maximum just before activity termination in agreement with our results from smaller networks (Fig. $8 A$ ). Interestingly, $\left[\mathrm{K}^{+}\right]_{\mathrm{o}}$ displayed complex nonlinear dynamics, reaching its peak soon after seizure onset and remaining relatively constant (except for low amplitude oscillations associated with tonic-clonic transitions) during a later phase. Seizure termination was followed by a period of postictal depression. The last appeared as a relatively small hyperpolarization of membrane voltage after termination of paroxysmal rhythm (Fig. $7 B$, inset). Postictal state lasted for several minutes. Neuronal excitability was reduced during postictal state that was sufficient to prevent spontaneous spiking in the model. As we previously described, this effect was mediated by residual elevation of intracellular sodium concentration that activated $\mathrm{Na}^{+} / \mathrm{K}^{+}$exchange pump forcing $\left[\mathrm{K}^{+}\right]_{\mathrm{o}}$ to remain below baseline (Figs. $3 A, 8 B$ ).

\section{Discussion}

In this study, we used a detailed conductance-based model of the neocortical network, incorporating intracellular and extracellular dynamics of $\mathrm{Na}^{+}$and $\mathrm{K}^{+}$ions as well as intracellular $\mathrm{Cl}^{-}$and $\mathrm{Ca}^{2+}$ dynamics to explore involvement of ionic concentration dynamics in the development and termination of paroxysmal seizure-like events. Sufficiently strong transient network stimulation led to selfsustained periodic transitions between tonic and clonic (bursting) activities mediated by $\left[\mathrm{K}^{+}\right]_{\mathrm{o}}$-dependent bistability between tonic and clonic network states. The duration of bursting periods was $\sim 80 \%$ of the duration of the entire seizure episode, similar to previous experimental findings (Nita et al., 2008). Progressive increase of $\left[\mathrm{Na}^{+}\right]_{\mathrm{i}}$ over the course of seizure reduced the range of $\left[\mathrm{K}^{+}\right]_{\mathrm{o}}$ that allows bistability to exist, ultimately making it impossible for paroxysmal oscillations to sustain after a few minutes of activity. This resulted in seizure termination and neuronal silence usually associated with postictal depression. The model revealed how complex interactions between sodium, potassium, and chloride ionic concentrations involving $\mathrm{Na}^{+} / \mathrm{K}^{+}$and KCC2 pumps and glial buffering may affect development of epileptiform events. Although our results are built on the background of previous computational studies (Kager et al., 2000; Bazhenov et al., 2004; Fröhlich et al., 2006; Somjen et al., 2008; Cressman et al., 2009; Ullah et al., 2009), this new study tied all of the past observations together to elucidate mechanisms of seizure dev- 
elopment, termination, and postictal depression in a unified model. The use of bifurcation analysis for exploring the mechanisms of epileptogenesis provided a way to generalize our findings across a wide range of conditions, since the only requirement for the existence of this mechanism is the similarity (or topological equivalence) of the state space between different models. Thus, we speculate that the ionic mechanism of seizure development and termination proposed in this study are common to the various models of neurons and provide an explanation for termination of epileptic states in experimental conditions.

Studies have shown that $\left[\mathrm{K}^{+}\right]_{\mathrm{o}}$ increases during seizure and that the increase of $\left[\mathrm{K}^{+}\right]_{\mathrm{o}}$ associated with epileptiform discharges in vivo may lead to seizure-like activity (Grafstein, 1956; Fertziger and Ranck, 1970; Heinemann et al., 1977; Jensen and Yaari, 1997). Recent studies on the pathophysiology of tissue from epileptic human patients (Hinterkeuser et al., 2000; Schröder et al., 2000; Binder and Steinhäuser, 2006) and animal epilepsy models (Grisar et al., 1992; Jansen et al., 2005; Ivens et al., 2007) revealed aberrations in $\left[\mathrm{K}^{+}\right]_{\mathrm{o}}$ regulation. Furthermore, recent computational studies revealed that a model pyramidal neuron can exhibit either tonic firing or bursting (clonic) state for the same level of $\left[\mathrm{K}^{+}\right]_{\mathrm{o}}$ (Bazhenov et al., 2004; Fröhlich et al., 2006; Cressman et al., 2009); such coexistence of different dynamical states is known as bistability. In the network model, bistability caused persistent slow transitions between tonic firing and bursting states (Fröhlich et al., 2006), closely resembling seizurelike activity seen in experimental studies (Timofeev and Steriade, 2004). More recently, it was shown that a sufficiently strong transient network stimulation can produce an increase of $\left[\mathrm{K}^{+}\right]_{\mathrm{o}}$ followed by activation of the positive-feedback loop between neuronal activity and $\left[\mathrm{K}^{+}\right]_{\mathrm{o}}$ leading to self-sustained tonic-clonic seizure (Fröhlich et al., 2010). These findings suggested $\left[\mathrm{K}^{+}\right]_{\mathrm{o}}$-dependent mechanism for the generation of realistic seizure-like activity but failed to explain spontaneous termination of epileptic seizures.

Although changes of the intracellular $\left[\mathrm{Na}^{+}\right]$are difficult to measure, studies suggest involvement of $\left[\mathrm{Na}^{+}\right]$ionic dynamics in the development of seizures (Timofeev and Steriade, 2004). Decrease of $\left[\mathrm{Na}^{+}\right]_{\mathrm{o}}$ has been reported during seizure-like activity (Meyer et al., 1961; Kraig and Nicholson, 1978; Dietzel et al., 1982) (for review, see Somjen, 2002). After seizure termination, $\left[\mathrm{Na}^{+}\right]_{\mathrm{o}}$ then returned slowly to the baseline while $\left[\mathrm{K}^{+}\right]_{\mathrm{o}}$ first reduced below its baseline level (Dietzel et al., 1982). Decrease of $\left[\mathrm{Na}^{+}\right]_{\mathrm{o}}$ during seizures in these studies was likely associated with increase of $\left[\mathrm{Na}^{+}\right]_{\mathrm{i}}$. Other indirect evidences support the role of $\mathrm{Na}^{+}$dynamics in seizure cessation. Many conventional antiepileptics (like phenytoin) act by reducing the activity of voltagesensitive $\mathrm{Na}^{+}$currents; although phenytoin increases seizure threshold, it also increases seizure duration (Ebert et al., 1997). This increase may arise because of slower accumulation of $\left[\mathrm{Na}^{+}\right]_{\mathrm{i}}$ in conditions of reduced voltage-sensitive $\mathrm{Na}^{+}$currents. Membrane hyperpolarizations caused by an increase in $\left[\mathrm{Na}^{+}\right]_{\mathrm{i}}$ after a burst of spiking have been reported under normal physiological conditions (Gustafsson and Wigström, 1983; Johnson et al., 1992), suggesting that $\left[\mathrm{Na}^{+}\right]_{\mathrm{i}}$ may accumulate during highly active epileptic states. Direct optical measurements of $\left[\mathrm{Na}^{+}\right]_{\mathrm{i}}$ showed that repetitive stimulation results in progressive increase of $\left[\mathrm{Na}^{+}\right]_{\mathrm{i}}$ by $4-10 \%$ over baseline, depending on the duration of the repetitive firing (Fleidervish et al., 2010). During the periods of simulated seizure, the $\left[\mathrm{Na}^{+}\right]_{\mathrm{i}}$ increased by $\sim 9 \%$ in our model, in agreement with results of this experimental study. All these experimental data support our model predictions that progressive increase of $\left[\mathrm{Na}^{+}\right]_{\mathrm{i}}$ over the course of seizure may be an important factor triggering termination of paroxysmal oscillation. From a biophysical perspective, the role of $\left[\mathrm{Na}^{+}\right]_{\mathrm{i}}$ accumulation in termination of seizure can be linked to the electrogenic nature of $\mathrm{Na}^{+} / \mathrm{K}^{+}$exchange pump (Rang and Ritchie, 1968). This pump transports two $\mathrm{K}^{+}$ions into the cell for every three $\mathrm{Na}^{+}$ ions that are removed; therefore, it generates outward electrical current. Strong activation of $\mathrm{Na}^{+} / \mathrm{K}^{+}$exchange pump by $\left[\mathrm{Na}^{+}\right]_{\mathrm{i}}$ increase may therefore change balance of excitatory and inhibitory currents leading to termination of seizure.

Our model predicts the important role of intracellular $\mathrm{Cl}^{-}$ dynamics during seizure. Previous experimental studies have shown that the reversal potential for $\mathrm{GABA}_{\mathrm{A}}$ changes significantly from approximately -70 to $-40 \mathrm{mV}$ during the initial stage of the seizure (Timofeev et al., 2002). In agreement with these experimental data, the $\left[\mathrm{Cl}^{-}\right]_{\mathrm{i}}$ increased in our model during the initial phase of seizure. We found that increase in $\left[\mathrm{Cl}^{-}\right]_{\mathrm{i}}$ had an opposite effect to seizure duration compared with increase of $\left[\mathrm{Na}^{+}\right]_{\mathrm{i}}$. For higher values of $\left[\mathrm{Cl}^{-}\right]_{\mathrm{i}}$, the range of extracellular $\mathrm{K}^{+}$concentrations in which the neuron displayed bistability was expanded, which promoted existence and stability of epileptic state. Increasing the efficiency of KCC2 pump limited increase of $\left[\mathrm{Cl}^{-}\right]_{\mathrm{i}}$ and reduced seizure duration in our model.

After termination of paroxysmal activity, $\left[\mathrm{Na}^{+}\right]_{\mathrm{i}}$ remained elevated and then slowly returned to its baseline level from the action of $\mathrm{Na}^{+} / \mathrm{K}^{+}$exchange pump. This slow timescale for returning of $\left[\mathrm{Na}^{+}\right]_{\mathrm{i}}$ to its baseline led to decrease of $\left[\mathrm{K}^{+}\right]_{\mathrm{o}}$ below its baseline level. The lower than baseline $\left[\mathrm{K}^{+}\right]_{\mathrm{o}}$ and increased $\left[\mathrm{Na}^{+}\right]_{\mathrm{i}}$, immediately after termination of seizure, mediated low excitability and relatively hyperpolarized membrane voltage state resembling postictal depression state of neurons. Several experimental studies previously confirmed the lower than baseline $\left[\mathrm{K}^{+}\right]_{\mathrm{o}}$ level after termination of seizure (Fig. 3B) (Heinemann et al., 1977; Jensen and Yaari, 1997). In the large-scale network model with background low-rate spiking activity mediated by external noise, the postictal depression state was evident as a state of silence that lasted for a few minutes after termination of seizure.

Other mechanisms could contribute to cessation of seizures. It was proposed that increase in $\left[\mathrm{Cl}^{-}\right]_{\mathrm{i}}$ over the course of seizure 
may change the balance between synaptic excitation and inhibition toward excitation and promote termination of epileptic oscillations (Fröhlich et al., 2005). However, this mechanism failed to explain the cause for postictal depression state. Termination of epileptiform activity in hippocampal slices in conditions of long and stable elevation of $\left[\mathrm{K}^{+}\right]_{\mathrm{o}}$ was preceded by the episodes of spreading depression (Bragin et al., 1997), suggesting transition to depolarization block. It was proposed that depolarization block would reduce outward flow of $\mathrm{K}^{+}$leading to removal of $\left[\mathrm{K}^{+}\right]_{\mathrm{o}}$ and seizure cessation. However, the question remains whether similar conditions could exist in vivo when diffusion and other factors are more efficient in controlling $\left[\mathrm{K}^{+}\right]_{\mathrm{o}}$ level during seizures. A reduction in $\mathrm{pH}$ was also proposed to cause termination of epileptic events. Indeed, a recent study showed that a genetic alteration in acidosis activated ion channels could prevent seizure termination (Ziemann et al., 2008). Nevertheless, all these observations do not rule out the mechanism of seizure termination depending on accumulation of $\left[\mathrm{Na}^{+}\right]_{\mathrm{i}}$ proposed in our study; rather, these results suggest that a combination of various factors may promote termination of seizures in different experimental conditions or clinical settings.

The model used in this study assumed fixed concentration for the extracellular calcium ions. However, the $\left[\mathrm{Ca}^{2+}\right]_{\mathrm{o}}$ is shown to be progressively reduced during seizure (Heinemann et al., 1977). This will decrease reliability of synaptic transmission and can affect long-range synchronization properties of cell firing during seizure (Boucetta et al., 2008). Nevertheless, the mechanism of seizure cessation explored in this study depends on the specific cellular properties, such as activation of $\mathrm{Na}^{+} / \mathrm{K}^{+}$exchange pump. This pump is driven by ATPase and represents an intrinsic factor that is not directly affected by the extracellular calcium. Similarly, we assumed constant concentration for the extracellular chloride ions. The main ground for this assumption was relatively high concentration of the chloride ions in the extracellular space that is less affected by the ion dynamics. Reduction of the $\left[\mathrm{Cl}^{-}\right]_{\mathrm{o}}$ was shown, however, to reduce seizure-like activity in the past experiments (Hochman and Schwartzkroin, 2000), which could also be a factor contributing to the termination of seizure. Chloride concentrations may be affected by chloride-bicarbonate exchanger; additional factors affecting calcium dynamics include intracellular buffering and calcium release form endoplasmic reticulum. Finally, dynamics of bicarbonate and some other anions was omitted from the model. The precise effect of all these factors during seizures need to be examined in the future studies. Cell swelling during seizures (Jing et al., 1994; Pérez-Pinzón et al., 1995) would restrict interstitial space and further amplify increases of the extracellular concentration of ions. Although these factors may affect quantitative results of the model simulations, they should not, however, qualitatively alter the predictions of this study, which are based on the electrogenic property of $\mathrm{Na}^{+} / \mathrm{K}^{+}$pump (Rang and Ritchie, 1968). The seizure cessation observed in our model was reliable to the many parameter alternations including severe alternation of the model structure itself, suggesting the structural stability of this phenomenon.

Our study makes predictions for new antiepileptic drugs and possible novel strategies for treating seizures. Since one of the main objectives of antiepileptic treatment is to increase seizure threshold, conventional antiepileptic drugs are designed to act on reducing activity of various sodium channels. However, according to our findings, such antiepileptic drugs would also increase the seizure duration as indeed observed in experimental studies (Ebert et al., 1997). Our model predicts that, after seizure initiation, $\left[\mathrm{Na}^{+}\right]_{\mathrm{i}}$ buildup is required for termination of epileptic events. This effect is reduced because of the action of existing antiepileptic drugs, leading to increased duration of seizure. Thus, we predict that, for seizures that are intractable to conventional antiepileptic drugs, the treatment preventing $\left[\mathrm{Cl}^{-}\right]_{\mathrm{i}}$ buildup, which is shown to modulate the duration of seizure, could provide a better strategy to control epileptogenesis.

\section{References}

Alzheimer C, Schwindt PC, Crill WE (1993) Modal gating of $\mathrm{Na}^{+}$channels as a mechanism of persistent $\mathrm{Na}^{+}$current in pyramidal neurons from rat and cat sensorimotor cortex. J Neurosci 13:660-673.

Bazhenov M, Timofeev I, Steriade M, Sejnowski TJ (2004) Potassium model for slow $(2-3 \mathrm{~Hz})$ in vivo neocortical paroxysmal oscillations. J Neurophysiol 92:1116-1132.

Bazhenov M, Timofeev I, Fröhlich F, Sejnowski TJ (2008) Cellular and network mechanisms of electrographic seizures. Drug Discov Today Dis Models 5:45-57.

Binder DK, Steinhäuser C (2006) Functional changes in astroglial cells in epilepsy. Glia 54:358-368.

Boucetta S, Chauvette S, Bazhenov M, Timofeev I (2008) Focal generation of paroxysmal fast runs during electrographic seizures. Epilepsia 49:1925-1940.

Bragin A, Penttonen M, Buzsáki G (1997) Termination of epileptic afterdischarge in the hippocampus. J Neurosci 17:2567-2579.

Cressman JR Jr, Ullah G, Ziburkus J, Schiff SJ, Barreto E (2009) The influence of sodium and potassium dynamics on excitability, seizures, and the stability of persistent states: I. Single neuron dynamics. J Comput Neurosci 26:159-170.

DeFazio RA, Keros S, Quick MW, Hablitz JJ (2000) Potassium-coupled chloride cotransport controls intracellular chloride in rat neocortical pyramidal neurons. J Neurosci 20:8069-8076.

Destexhe A, Mainen ZF, Sejnowski TJ (1994) Synthesis of models for excitable membranes, synaptic transmission and neuromodulation using a common kinetic formalism. J Comput Neurosci 1:195-230.

Dietzel I, Heinemann U, Hofmeier G, Lux HD (1982) Stimulus-induced changes in extracellular $\mathrm{Na}^{+}$and $\mathrm{Cl}^{-}$concentration in relation to changes in the size of the extracellular space. Exp Brain Res 46:73-84.

Ebert U, Cramer S, Löscher W (1997) Phenytoin's effect on the spread of seizure activity in the amygdala kindling model. Naunyn Schmiedebergs Arch Pharmacol 356:341-347.

Ermentrout B (2002) Simulating, analyzing, and animating dynamical systems. Philadelphia, PA: Society for Industrial and Applied Mathematics.

Fertziger AP, Ranck JB Jr (1970) Potassium accumulation in interstitial space during epileptiform seizures. Exp Neurol 26:571-585.

Fisher RS, van Emde Boas W, Blume W, Elger C, Genton P, Lee P, Engel J Jr (2005) Epileptic seizures and epilepsy: definitions proposed by the International League against Epilepsy (ILAE) and the International Bureau for Epilepsy (IBE). Epilepsia 46:470-472.

Fleidervish IA, Lasser-Ross N, Gutnick MJ, Ross WN (2010) $\mathrm{Na}^{+}$imaging reveals little difference in action potential-evoked $\mathrm{Na}^{+}$influx between axon and soma. Nat Neurosci 13:852-860.

Fröhlich F, Bazhenov M (2006) Coexistence of tonic firing and bursting in cortical neurons. Phys Rev E Stat Nonlin Soft Matter Phys 74:031922.

Fröhlich F, Bazhenov M, Timofeev I, Sejnowski TJ (2005) Maintenance and termination of neocortical oscillations by dynamic modulation of intrinsic and synaptic excitability. Thalamus Relat Syst 3:147-156.

Fröhlich F, Bazhenov M, Timofeev I, Steriade M, Sejnowski TJ (2006) Slow state transitions of sustained neural oscillations by activity-dependent modulation of intrinsic excitability. J Neurosci 26:6153-6162.

Fröhlich F, Bazhenov M, Iragui-Madoz V, Sejnowski TJ (2008) Potassium dynamics in the epileptic cortex: new insights on an old topic. Neuroscientist 14:422-433.

Fröhlich F, Sejnowski TJ, Bazhenov M (2010) Network bistability mediates spontaneous transitions between normal and pathological brain states. J Neurosci 30:10734-10743.

Grafstein B (1956) Mechanism of spreading cortical depression. J Neurophysiol 19:154-171.

Grisar T, Guillaume D, Delgado-Escueta AV (1992) Contribution of $\mathrm{Na}^{+}, \mathrm{K}^{+}$ATPase to focal epilepsy: a brief review. Epilepsy Res 12:141-149.

Grubb MS, Burrone J (2010) Activity-dependent relocation of the axon initial segment fine-tunes neuronal excitability. Nature 465:1070-1074. 
Gustafsson B, Wigström H (1983) Hyperpolarization following long-lasting tetanic activation of hippocampal pyramidal cells. Brain Res 275:159-163.

Heinemann U, Lux HD, Gutnick MJ (1977) Extracellular free calcium and potassium during paroxsmal activity in the cerebral cortex of the cat. Exp Brain Res 27:237-243.

Hinterkeuser S, Schröder W, Hager G, Seifert G, Blümcke I, Elger CE, Schramm J, Steinhäuser C (2000) Astrocytes in the hippocampus of patients with temporal lobe epilepsy display changes in potassium conductances. Eur J Neurosci 12:2087-2096.

Hochman DW, Schwartzkroin PA (2000) Chloride-cotransport blockade desynchronizes neuronal discharge in the "epileptic" hippocampal slice. J Neurophysiol 83:406-417.

Ivens S, Kaufer D, Flores LP, Bechmann I, Zumsteg D, Tomkins O, Seiffert E, Heinemann U, Friedman A (2007) TGF-beta receptor-mediated albumin uptake into astrocytes is involved in neocortical epileptogenesis. Brain 130:535-547.

Izhikevich EM (2006) Dynamical systems in neuroscience. Cambridge, MA: MIT.

Jansen LA, Uhlmann EJ, Crino PB, Gutmann DH, Wong M (2005) Epileptogenesis and reduced inward rectifier potassium current in tuberous sclerosis complex-1-deficient astrocytes. Epilepsia 46:1871-1880.

Jensen MS, Yaari Y (1997) Role of intrinsic burst firing, potassium accumulation, and electrical coupling in the elevated potassium model of hippocampal epilepsy. J Neurophysiol 77:1224-1233.

Jing J, Aitken PG, Somjen GG (1994) Interstitial volume changes during spreading depression (SD) and SD-like hypoxic depolarization in hippocampal tissue slices. J Neurophysiol 71:2548-2551.

Johnson SW, Seutin V, North RA (1992) Burst firing in dopamine neurons induced by $N$-methyl-D-aspartate: role of electrogenic sodium pump. Science 258:665-667.

Kager H, Wadman WJ, Somjen GG (2000) Simulated seizures and spreading depression in a neuron model incorporating interstitial space and ion concentrations. J Neurophysiol 84:495-512.

Kraig RP, Nicholson C (1978) Extracellular ionic variations during spreading depression. Neuroscience 3:1045-1059.

Kuznetsov IA (1995) Elements of applied bifurcation theory. New York: Springer.

Mainen ZF, Sejnowski TJ (1996) Influence of dendritic structure on firing pattern in model neocortical neurons. Nature 382:363-366.

Meyer JS, Gotoh F, Tazaki Y (1961) Inhibitory action of carbon dioxide and acetazoleamide in seizure activity. Electroencephalogr Clin Neurophysiol 13:762-775.

Niedermeyer E (2002) Lennox-gastaut syndrome. Clinical description and diagnosis. Adv Exp Med Biol 497:61-75.

Nita DA, Cissé Y, Timofeev I (2008) EPSP depression following neocortical seizures in cat. Epilepsia 49:705-709.

O’Leary T, van Rossum MC, Wyllie DJ (2010) Homeostasis of intrinsic excitability in hippocampal neurones: dynamics and mechanism of the response to chronic depolarization. J Physiol 588:157-170.

Payne JA, Rivera C, Voipio J, Kaila K (2003) Cation-chloride co-transporters in neuronal communication, development and trauma. Trends Neurosci 26:199-206.

Pérez-Pinzón MA, Tao L, Nicholson C (1995) Extracellular potassium, volume fraction, and tortuosity in rat hippocampal CA1, CA3, and cortical slices during ischemia. J Neurophysiol 74:565-573.

Rang HP, Ritchie JM (1968) On the electrogenic sodium pump in mammalian nonmyelinated nerve fibres and its activation by various external cations. J Physiol 196:183-221.

Rinzel J, Ermentrout GB (1989) Methods in neuronal modeling: from synapses to networks. Cambridge, MA: MIT.

Schröder W, Hinterkeuser S, Seifert G, Schramm J, Jabs R, Wilkin GP, Steinhäuser C (2000) Functional and molecular properties of human astrocytes in acute hippocampal slices obtained from patients with temporal lobe epilepsy. Epilepsia 41 [Suppl 6]:S181-S184.

Seigneur J, Timofeev I (2011) Synaptic impairment induced by paroxysmal ionic conditions in neocortex. Epilepsia 52:132-139.

Somjen GG (2002) Ion regulation in the brain: implications for pathophysiology. Neuroscientist 8:254-267.

Somjen GG, Kager H, Wadman WJ (2008) Computer simulations of neuron-glia interactions mediated by ion flux. J Comput Neurosci 25:349-365.

Steriade M (2003) Neuronal substrates of sleep and epilepsy. Cambridge, MA: Cambridge UP.

Timofeev I, Steriade M (2004) Neocortical seizures: initiation, development and cessation. Neuroscience 123:299-336.

Timofeev I, Grenier F, Bazhenov M, Sejnowski TJ, Steriade M (2000) Origin of slow cortical oscillations in deafferented cortical slabs. Cereb Cortex 10:1185-1199.

Timofeev I, Grenier F, Steriade M (2002) The role of chloride-dependent inhibition and the activity of fast-spiking neurons during cortical spikewave electrographic seizures. Neuroscience 114:1115-1132.

Tsodyks MV, Markram H (1997) The neural code between neocortical pyramidal neurons depends on neurotransmitter release probability. Proc Natl Acad Sci U S A 94:719-723.

Ullah G, Cressman JR Jr, Barreto E, Schiff SJ (2009) The influence of sodium and potassium dynamics on excitability, seizures, and the stability of persistent states. II. Network and glial dynamics. J Comput Neurosci 26:171-183

van Welie I, van Hooft JA, Wadman WJ (2006) Background activity regulates excitability of rat hippocampal CA1 pyramidal neurons by adaptation of a $\mathrm{K}^{+}$conductance. J Neurophysiol 95:2007-2012.

Wang XJ, Liu Y, Sanchez-Vives MV, McCormick DA (2003) Adaptation and temporal decorrelation by single neurons in the primary visual cortex. J Neurophysiol 89:3279-3293.

Ziburkus J, Cressman JR, Barreto E, Schiff SJ (2006) Interneuron and pyramidal cell interplay during in vitro seizure-like events. J Neurophysiol 95:3948-3954.

Ziemann AE, Schnizler MK, Albert GW, Severson MA, Howard MA, Welsh MJ, Wemmie JA (2008) Seizure termination by acidosis depends on ASIC1a. Nat Neurosci 11:816-822. 